Portland State University

PDXScholar

1986

\title{
The effects of two management techniques on the generalization of a syntax structure
}

Karin Jeanne Goodling

Portland State University

Follow this and additional works at: https://pdxscholar.library.pdx.edu/open_access_etds

Part of the Speech Pathology and Audiology Commons, and the Syntax Commons Let us know how access to this document benefits you.

\section{Recommended Citation}

Goodling, Karin Jeanne, "The effects of two management techniques on the generalization of a syntax structure" (1986). Dissertations and Theses. Paper 3631.

https://doi.org/10.15760/etd.5499

This Thesis is brought to you for free and open access. It has been accepted for inclusion in Dissertations and Theses by an authorized administrator of PDXScholar. Please contact us if we can make this document more accessible: pdxscholar@pdx.edu. 
AN ABSTRACT OF THE THESIS OF Karin Jeanne Goodling for the Master of Science in Speech Communications, with an emphasis in Speech Pathology/Audiology, presented May 6, 1986 .

Title: The Effects of Two Management Techniques on the Generalization of a Syntax structure.
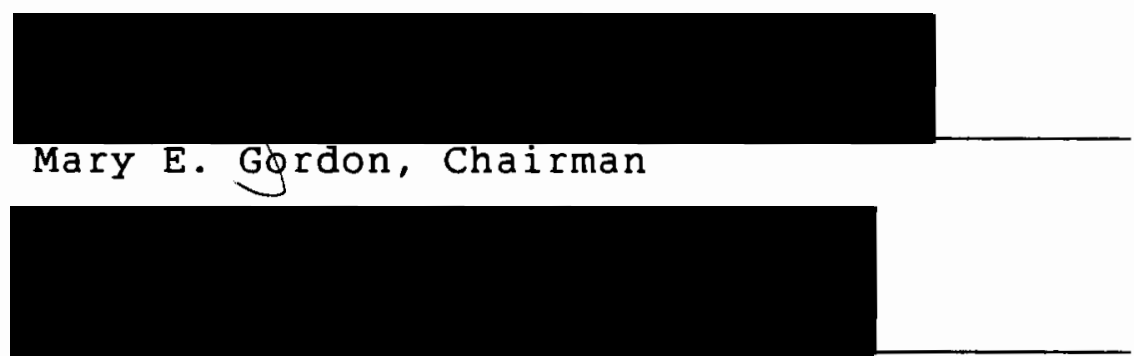

Robert L. Cásteet

The effectiveness of any language training program is determined by generalization of the clinically trained behaviors to spontaneous speech (Hedge, Noll and Pecora, 1979). Traditional language programs which employ operant procedures to establish the behavior in the clinic and reinforcement from family, teachers and peers in a variety of settings to obtain generalization, have been successful in establishing the use of grammatical rules in the clinic setting, but reportedly have failed to promote generalization (Rees, 1978). Recent literature in the areas of 
semantics and pragmatics has produced a trend toward teaching language in natural contexts. The purpose of this study was to investigate: 1) whether a group taught with a traditional syntax program would generalize the trained structure to spontaneous speech, 2) whether a group trained with a traditional syntax program in combination with nontraditional methods (natural context) would evidence generalization, 3) whether one of the above methods would evidence greater, lesser or the same generalization and 4) which method would take fewer, the same or greater number of sessions.

Six subjects ranging in age from 4 years 7 months to 5 years 10 months were selected. All demonstrated normal hearing, normal receptive language abilities and delayed expressive language abilities. Subjects were matched according to Mean Length of Utterance and omission of a particular grammatical rule. One of each pair was randomly placed in one of the two intervention groups. Method $\mathrm{A}$ was the Monterey Language Program and Method $B$ was the Monterey Language Program used during the first half of each session and play activities during the second half. Intervention consisted of three twenty-five minute sessions a week for twelve sessions. A criterion test, devised to measure generalization, was administered before intervention, three times during intervention and one week following intervention. 
Results indicated that one subject trained with Method A evidenced generalization of the structure, one failed to demonstrate generalization and the other was beginning to show generalization. These results are not as good as would be expected from Gray and Ryan's (1973) report, but better than would be expected from both Mulac and Tomlinson's (1977) study and reports from the field of poor generalization results of traditional programs. Two subjects trained with Method B evidenced generalization of the structure while one did not. Therefore, it appears that Method B was slightly more effective than Method A. However, if subject A3 had entered the study with previous remediation experience, he may also have achieved generalization and then the methods would have been equally effective. It is interesting to note, that the two subjects who failed to generalize, one trained with Method $A$ and the other with Method B, exhibited articulation disorders as well as expressive language delays. of the subjects who did generalize, the two Method $B$ subjects took fewer sessions than did the two Method $A$ subjects. As two of these subjects, $A 1$ and $B 1$, were very well matched on several variables, the difference in the rate of generalization may have been due to the methods used. However, results are at very best tentative, as with such a small sample individual subject variables may have influenced the generalization results. A multiple 
baseline study may help determine whether the difference was due to a teaching method or to subjects' individual characteristics. 
THE EFFECTS OF TWO MANAGEMENT TECHNIQUES

ON THE GENERALIZATION OF A

SYNTAX STRUCTURE

by

KARIN JEANNE GOODLING

A thesis submitted in partial fulfillment of the requirements for the degree of

MASTER OF SCIENCE IN SPEECH COMMUNICATION:

with an emphasis in

SPEECH PATHOLOGY/AUDIOLOGY

Portland State University

1986 
TO THE OFFICE OF GRADUATE STUDIES AND RESEARCH:

The members of the Committee approve the thesis of Karin Jeanne Goodling presented May 6, 1986.

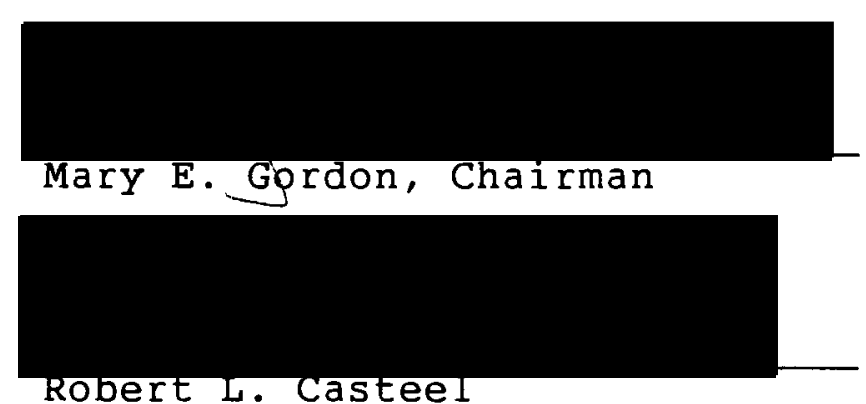

APPROVED :

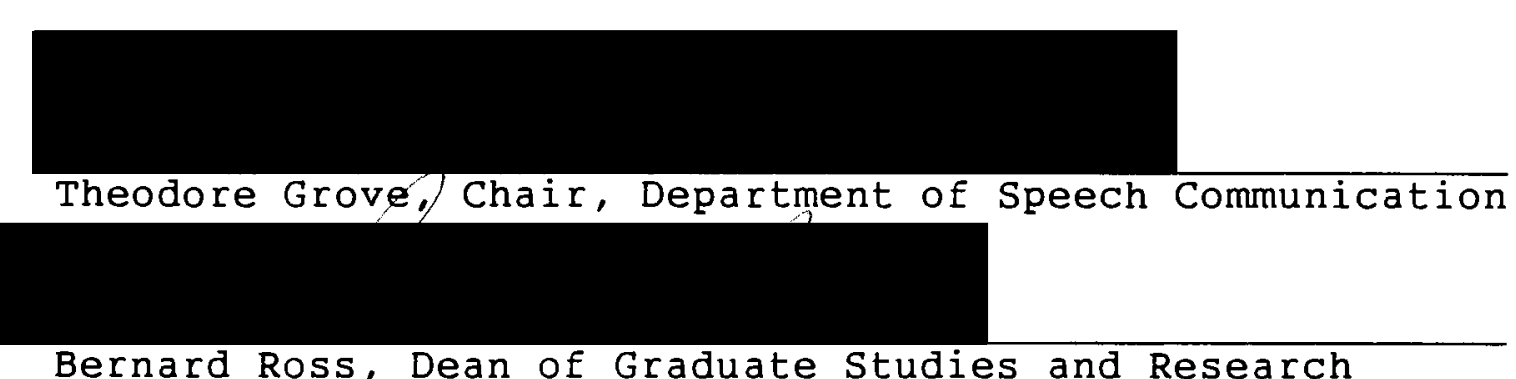

Bernard Ross, Dean of Graduate Studies and Research 


\section{ACKNOWLEDGMENTS}

There are many people who helped me complete this thesis. Mary Gordon, my thesis director, deserves special thanks. Without her persistent and friendly guidance, my thesis would be yet collecting dust in a closet unfinished.

Dr. Casteel deserves special recognition for helping to develop in me a critical, rather than all accepting view, when reading literature. Difficult as they were, the stuttering chapter critiques were successful.

I am grateful to Dr. Dieterich for serving as graduate council representative on my thesis committee. He spent a lot of time reading and studying my thesis and asked very appropriate and insightful questions. I enjoyed his discussions very much.

There were several people indispensable to the operation of my study. Undergraduate students, Janet Holstein, Cathy Murphy and Debbie Fuchigami were excellent testers. I thoroughly enjoyed all of my subjects and have nothing but great respect for their parents. They are very dedicated and loving parents and deserve recognition.

I am very grateful to Cheri Schoebel and Beth Grant for putting this thesis into its final form.

Finally I would like to acknowledge the support of my graduate "buddies" and last but not least, the patience 
and help of my husband, my mother, and my mother-in-law. 
TABLE OF CONTENTS

PAGE

ACKNOWLEDGMENTS

i i i

LIST OF TABLES . . . . . . . . . . . . . . . . . . . viii

LIST OF FIGURES . . . . . . . . . . . . . . . . . . ix

CHAPTER

I INTRODUCTION • • . . . . . . . . . . . . . 1

Statement of Purpose . . . . . . . . 6

I I REVIEW OF THE LITERATURE . . . . . . . . . . 7

Theories of Language Acquisitions . . . $\quad 8$

Behavioral Theory

Transformational Grammar Theory

Review of Operant Studies and Programs . 10

Current Theories of Language Acquisition . 18

Semantic Theory

Pragmatic Theory

Implications for Intervention . . . . . 25

II I METHODS AND PROCEDURES . . . . . . . . . 32

General Plan . . . . . . . . . . 32

Subjects . . . . . . . . . . . . . 33

Review of Case Files

Variables Screened and Instrumentation Used

Selecting Subjects with Matched

Abilities 
CHAPTER

PAGE

Program Descriptions

$\frac{\text { Monterey Language Programs (MLP) }}{\text { Method A }}$

Monterey Language/Natural Context, Method $B$

Investigator's Training in the MLP

Criterion Test. . . . . . . . . . 42

Procedures............ . . . 47

Data Analysis . . . . . . . . . . 48

IV RESULTS AND DISCUSSION . . . . . . . . 49

Results . . . . . . . . . . . . . 49

Discussion . . . . . . . . . . 65

$\mathrm{V}$ SUMMARY AND IMPLICATIONS . . . . . . . . . 78

Summary . . . . . . . . . . . . . . 78

Implications . . . . . . . . . . 80

Clinical

Research

SELECTED BIBLIOGRAPHY

A PERMISSION FORM A . . . . . . . . . . . . 92

B PERMISSION FORM B 1 . . . . . . . . . . 93

C PERMISSION FORM B 2 . . . . . . . . . . . . 94

D DESCRIPTION OF SUBJECTS • • • . • . • . . . 95

E MLP LANGUAGe CURRiculum . . . . . . . . . . 97

F MLP CRITERION TEST SAMPLE QUESTIONS . . . . . 98

G MLP DELIVERY VARIABLES . . . . . . . . . . 99

H ONE OF THE TWO MLP PROGRAMS USED . . . . . . 100 
vii

CHAPTER

PAGE

I PLAY INTERACTION PATTERNS . . . . . . . . 105

J CRITERION TEST . . . . . . . . . . . . 106

K Play ACtivities . . . . . . . . . . . . . 111 


\section{LIST OF TABLES}

TABLE

PAGE

I Matching of Subjects on Mean Length of

Utterance (MLU) and Errored Structure . . 37

I Method A, Traditional Syntax Program

Pre-Post Criterion Test Scores . . . . . 51

II Method B, Traditional Syntax program in

Combination with Nontraditional Methods

Pre-Post Criterion Test Scores... . . . 53 
LIST OF FIGURES

FIGURE

PAGE

1. Post-Criterion Test Scores for Pair 1. . . 55

2. Post-Criterion Test Scores for Pair 2 . . . 56

3. Post-Criterion Test Scores for Pair 3... . . 57

4. Post-Criterion Test Task 1 Scores for Method A and Method B Subjects . . . . . . . 58

5. Post-Criterion Test Scores for Subject A2 and Subject B3... . . . . . . . . . . 59

6. Subject $A 1, A 3, B 1$ and $B 2$ 's Scores on TASK 1

for Pre-Criterion Test, Criterion Test 1,

Criterion Test 2, Criterion Test 3 and Post-Criterion Test . . . . . . . . . 60

7. Subject A1, A3, B1 and B2's Scores on TASK 2

for Pre-Criterion Test, Criterion Test 1,

Criterion Test 2, Criterion Test 3 and

Post-Criterion Test . . . . . . . . 64

8. Subject $A 2$ and $B 3^{\prime} \mathrm{s}$ Scores on TASK 2 for

Pre-Criterion Test, Criterion Test 1,

Criterion Test 2, Criterion Test 3 and

Post-Criterion Test . . . . . . . . 65 
CHAPTER I

INTRODUCT ION

Language training requires programming of two facets; the first facet concerns establishment of the desired behavior and the second facet relates to generalization of the established behavior to new environments (Garcia, 1974; Garcia and DeHaven, 1974; Guess, Sailor and Baer, 1974; Rees, 1978; Ruder, 1978). The end goal of language training is to improve the client's communication in his natural environment (Harris, 1975). Therefore, the effectiveness of any language training program is determined by generalization of clinically-trained behaviors to new situations, settings and persons (Hedge, Noll and Pecora, 1979). Speech-language pathologists agree that lack of generalization of what is learned in the clinic setting to spontaneous use outside of that setting is a significant problem faced in language training (Mulac and Tomlinson, 1977; Guess, Keogh and Sailor, 1978; Rees, 1978).

Through the use of operant procedures, clinicians and researchers have found it relatively easy to accomplish the first facet of language programming, i.e., establishment of verbal behavior in response to stimuli used in training (Sailor, Guess and Baer, 1973; Harris, 1975; 
Guess et al., 1978). Several studies have demonstrated success in teaching children grammatical rules within the clinical setting (Guess, Sailor, Rutherford and Baer, 1968; Schumaker and Sherman, 1970; Wheeler and Sulzer, 1970; Sailor and Taman, 1972; Lutzher and Sherman, 1974). The second facet of language programming, i.e., generalization of the clinically trained behavior to new environments, has not received much experimental attention (Garcia, 1974; Harris, 1975). According to Guess, Keogh and Sailor (1978), language training programs have not yet provided data demonstrating the extent to which spontaneous language can be taught. Therefore, even though establishment of grammatical rules in the clinical setting has been substantiated experimentally, it appears that generalization of those rules to spontaneous speech has not yet become a reliably scheduled outcome of language training (Garcia, 1974). Harris (1975) reviewed language training studies which used operant procedures and found that many of them did not make an attempt to program for generalization, and of, the ones which did program for generalization, few actually measured it.

In a review of language training programs which did plan for generalization, it was found that the same general format was used consistently among them (Risley and Wolf, 1968; Sloane, Johnston and Harris, 1968; Bricker and Bricker, 1970; Hartung, 1970; Gray and Ryan, 1973; 
Sailor et al., 1973). In general, the first phase of the program is directed towards establishing a specified verbal response to stimuli, usually pictures. This is accomplished through imitation and differential reinforcement. The clinician presents a picture with a verbal model for the client to imitate. The imitative prompts are gradually faded until the desired response is obtained with no model or prompt. After the client demonstrates he can produce the desired response consistently in the clinic without a model, the second phase is initiated. In this phase, family members, teachers and even other children are used as reinforcing agents. They reinforce correct usage of the target in a variety of settings such as in the home, in the classroom and on the playground.

According to Ruder and Smith (1974), the most widely used language training programs are ones which employ operant procedures and programming, such as described in the previous paragraph. Yet, Rees (1978) reported that language clinicians repeatedly described clients who, after language training, produce a given construction on demand but fail to do so spontaneously or appropriately. It can no longer be assumed that because a client knows a specific application of a grammatical rule that he will use that rule broadly to communicate (Hart and Risley, 1968; Garcia, 1974; Mulac and Tomlinson, 1977; Guess et al., 1978; Rees, 1978; Ruder, 1978). Perhaps, clinicians 
are not systematically training parents and teachers to reinforce correct usage of the target outside of clinic or maybe parents and teachers are being trained but are not following through consistently. Perhaps different procedures for programming generalization would be more effective. Unfortunately, research studying the relative effectiveness of different procedures on the process of language generalization is noticeably lacking in the literature (Garcia, 1974; Harris, 1975; Mulac and Tomlinson, 1977; Muma, 1978). There are, however, implications for intervention which can be drawn from the most current research in semantics and pragmatics.

Language programs traditionally have approached language as a set of sentences to be mastered independently of one's intent to code a particular idea for a particular purpose (Muma, 1978). In other words, aspects of communication have been separated out of communicative context. Syntax, semantics and pragmatics, however, are inseparable, i.e., linguistic forms (structure) are used to communicate ideas (semantics) with a particular purpose in mind (pragmatics) (McLean and Snyder-McLean, 1978). Miller (1981) states the more experience a child has in constructing language structures to match real, rather than contrived, social or contextual constraints, the more likely he is to improve as an effective and appropriate communicator. In short, Miller and many others (Harris, 
1975; Holland, 1975; Hubbel1, 1977; McCormick and Elder, 1978; MCLean and Snyder-McLean, 1978; Lucas, 1980) advocate the use of natural contexts in language training, in order that the child can practice using the trained structures in a meaningful way to deal with information which interests him.

In this writer's opinion, this does not mean structural approaches using operant procedures should be discontinued, but rather, as Muma (1978) suggests, the limits of these procedures must be recognized. Operant procedures of imitation and differential reinforcement have been effective in establishing syntactical structures. It is methods of programming generalization of the established syntactical structure to spontaneous speech, which have not been substantiated (Garcia, 1974; Guess et al., 1974; Harris, 1975; Guess et al., 1978). When traditional syntax programs teach the functional use of a particular structure, it is left until the last step of the program. Rather than wait until the last step of the program to teach functional use of a structure, it is suggested by this writer, that operant procedures be used to establish the syntactical structure and natural contexts, such as play, be used concurrently to teach the use of the structure. 
STATEMENT OF PURPOSE

The purpose of this study was to compare the generalization of a syntactical structure by children who were trained by two methods of instruction. One group was taught a syntactical structure using a traditional syntax program, in which, generalization of the structure was the last step of the program. A second group was taught the same syntactical structure using traditional methods in combination with nontraditional methods (natural contexts) concurrently, thereby promoting generalization of the structure from the beginning of the program. Answers to the following questions were sought:

1. Will children taught with a traditional syntax program evidence generalization of the trained syntactical structure?

2. Will children taught with a traditional syntax program in combination with nontraditional methods (natural contexts) concurrently, evidence generalization of the trained syntactical structure?

3. Will children taught with a traditional syntax program in combination with nontraditional methods (natural contexts) concurrently, evidence greater, lesser, or the same generalization of the trained syntactical structure as the children taught with a traditional syntax program?

4. If children in both groups evidence generalization of the trained syntactical structure, will the children taught with a traditional syntax program in combination with nontraditional methods (natural contexts) concurrently, take fewer, the same or greater number of sessions than the children taught with a traditional syntax program? 
CHAPTER II

REVIEW OF THE LITERATURE

The ability to communicate is a critical component of human development (Bricker and Bricker, 1970). Consequently, children who are handicapped in language development need remedial training directed towards improving their communication skills. Today many language training programs exist for the purpose of accomplishing this goal (Guess, Keogh and Sailor, 1978). The effectiveness of these programs must be determined by generalization of the clinically trained target to new situations, settings and persons, for, only if the child uses the structure outside of the clinic will it improve his communication (Hedge, Noll, and Pecora, 1979). Generalization is reported as a significant problem faced in language training (Mulac and Tomlinson, 1977; Guess et al., 1978; Rees, 1978). Difficulties encountered while attempting to obtain any desired goal, such as generalization, requires that the procedures and theories underlying those procedures be scrutinized.

Language training programs are often based on theories of "what" language is and "how" it is acquired (McLean and Snyder-McLean, 1978; Muma, 1978; Schiefelbusch, 1978). Theories are merely premises based upon research 
and therefore, are subject to change as new investigations add to the knowledge in a field. Bruner (1975) provides a good summary on the development of thoughts concerning language acquisition. He follows the progression of thoughts from viewing language as an operant behavior (behaviorism), to describing language in terms of grammatical rules (transformational grammar), to a look at the underlying meanings of structures (semantics) and most currently an interest in how language is used to fulfill intentions (pragmatics). As theories of language acquisition change, so must procedures for teaching language change.

\section{THEORIES OF LANGUAGE ACQUISITION}

The two most dominant theories underlying the majority of language intervention programs are the behavioral theory and the transformational grammar theory (Lee, 1974b; Ruder and Smith, 1974). The behavioral theory provides a concept of "how" language is acquired which has readily translated into procedural practices for language training programs. The transformational grammar theory, on the other hand, provides a description of "what" children learn when they acquire language, thereby, supplying goals or content for language training programs.

Behavioral Theory

Skinner (1957) described language acquisition in terms of learning theory. According to Skinner, all 
aspects of language learning, including phonological, lexical and grammatical aspects, are learned as any other form of learned behavior is, i.e., through conditioning and shaping by environmental reinforcement. Verbal behaviors, therefore, are operant behaviors whose rates can be controlled by the manipulation of the consequences which follow these behaviors. Since behaviorists consider only observable, quantifiable behavior (Skinner, 1957), the question of "what" a child learns when acquiring language is described as verbal behaviors, i.e., the final product of language, the linguistic code.

\section{Transformational Grammar Theory}

Chomsky (1957) developed transformational grammar in an effort to describe the rules underlying the generative use of language. In a review of Skinner's (1957) book Verbal Behavior, Chomsky (1959) rejected the behavioral theory description of the language acquisition process, stating that this theory could not account for the generative use of language. According to the transformational grammar theory, only through an understanding of the grammatical relationships of subject, verb and object, is a person able to understand and produce an infinite number of sentences. To understand or produce a sentence such as, "The bone was eaten by the dog.", a person must know how each functions in the sentence, i.e., that "bone" 
functions as the object of the sentence and "dog" as the subject.

Psycholinguists, such as McNeil (1966), interpreted Chomsky's theory and stated that children have an innate ability to discover the grammatical relationships of subject, verb and object, provided they are sufficiently exposed to adult language in the environment. In brief, psycholinguists define "what" children learn as grammatical rules and "how" children learn these rules is through an innate capacity to discover them in speech.

According to Lee (1974b), the biggest contribution of transformational grammar to language training programs has been the generation of a tremendous amount of research studying the development of grammatical rules in normal language acquisition. Speech-language pathologists using operant language training programs often depend upon developmental information from psycholinguistic research to plan the content of their programs (Lee, 1974b).

\section{REVIEW OF OPERANT STUDIES AND PROGRAMS}

In the years following skinner's (1957) description of the operant nature of language, considerable attention was directed toward applying learning theory to the development of language skills among language deficient individuals (Hedge and Gierut, 1979). The two concepts of operant procedures and programmed instruction were implemented 
in a number of operant conditioning studies, and were eventually used to design systematic language training programs. Programmed instruction, briefly, refers to the planned presentation of language to children in successively more difficult steps (Lee, 1974b). Operant procedures include the shaping of verbal responses through imitation and differential reinforcement. In brief, children are taught to imitate verbal responses, and then verbal prompts or models are faded, so as to transfer speech from imitative control to control by appropriate stimulus conditions (Risley and wolfe, 1968).

Some of the first studies investigating the use of operant procedures to train language were case studies involving autistic and severely retarded children. Risley and Wolfe (1968) used operant procedures to teach language to autistic children. The steps used were: 1) elimination of disruptive behavior through time-out from positive reinforcement; 2) establishment of control over imitation through shaping and differential reinforcement; 3) naming, which involved appropriate verbal responses in the presence of pictures or objects (imitative prompts were faded out); 4) establishment of phrases, through similar procedures as used in teaching naming; and finally, 5) appropriate speech as systematically reinforced with a variety of individuals in a variety of settings.

Sloane, Johnston and Harris (1968) followed nearly 
the same format as Risley and Wolfe (1968) in teaching language to severely retarded and emotionally disturbed children. In both studies, subjects were reported to generalize, although infrequently, their new verbal behaviors to settings other than those used in training. However, reports of generalization were not experimental, but rather, of the anecdotal type (Guess, Sailor and Baer, 1974).

In addition to case reports, a series of empirical studies have explored the teaching of grammatical forms using imitation and differential reinforcement. As a group, these studies have indicated that grammatical rules, once trained in the context of a limited number of stimuli, generalized to new and nontrained stimuli.

Guess, Sailor, Rutherford and Baer (1968) taught a severely retarded girl to use the plural morpheme correctly when presented with two objects. During training, positive reinforcement was contingent upon correct imitations of singular and plural verbalization in response to a set of objects presented to the subject singly and in pairs. Eventually, the subject responded correctly to the presented object or objects with no model. To test whether the learned grammatical rule generalized to different stimuli than used in training, probes were conducted in which new objects were presented to the subject. The subject labeled these new objects 
correctly even though she had never been trained with them. Several other studies followed this same format, i.e., teaching a grammatical rule to specific stimuli, usually pictures or objects, and then probing with untrained pictures or objects to test for generalization of the rule. Schumaker and Sherman (1970) taught retarded children, through the use of imitation and reinforcement procedures, to produce past and present tense forms of verbs in response to verbal requests. The children successfully produced the correct past and present tense forms in response to untrained verb presentations. In another study done by wheeler and sulzer (1970), a subject, who spoke telegraphic English, was trained to use a particular sentence form that included articles and verbs to describe a set of pictures. The trained sentence form generalized to a set of untrained pictures. Lutzher and Sherman (1974) taught retarded and normal children to use sentences involving plural and singular subject-verb agreement in response to pictures. As was found in the other studies, probe testing for generalization to untrained pictures revealed that imitation and reinforcement procedures can be used to teach generative grammatical rules.

In none of the experiments described above, was generalization examined in other settings, on different tasks, or with different people. Two studies examined 
generalization under less restricted procedures. Martin (1975) taught the use of descriptive adjectives within sentences to two retarded children. The children imitated twelve specific sentences (without pictures), containing six different animals and specific adjectives, for example: "The black bear is eating.", in a morning session. In the afternoon, a different experimenter presented twelve Peabody animal pictures and asked the subject to describe the pictures. Six of the different animals depicted in the pictures had been used in sentences in the morning session, and the other six had not. It was found that the subjects used adjectives to describe all the pictures even though six of the animals had not been included in sentences in the morning sessions. Therefore, generalization measures were obtained in a slightly different task, with a different experimenter and in a different setting.

Hart and Risley (1968) went even further in their study and measured for generalization training to free play. They taught disadvantaged preschool children colors using the standard operant procedures of imitation and differential reinforcement. When the children reached criterion, they probed their spontaneous speech to see if the children were using what they "knew". They were not, so the experimenters decided to change their procedures. During play time the children were required to use colors 
when asking for toys or when asking for snack food. A probe of their spontaneous speech found that they were using colors even after the contingencies were withdrawn. The authors concluded that once the target was generated in free play, it was maintained even though the contingencies were removed. This study found that traditional methods were ineffective in modifying spontaneous speech until combined with other procedures.

An outgrowth of the research on teaching language using operant procedures has been the publication of systematic language training programs. Bricker and Bricker (1970), Hartung (1970) and Sailor, Guess and Baer (1973) wrote similar language training programs for severely language handicapped children. The procedures used and steps followed resemble the ones discussed in the case studies involving autistic and severely retarded children. A brief review of these follows. Attending behaviors are taught first, followed by motor imitation skills and vocal imitative skills, respectively. Next, a transition from vocal imitation to naming is accomplished. Phrases and sentences are taught next. All of these tasks are achieved through shaping procedures using imitative prompts, fading of these prompts and differential reinforcement of the desired behavior. The last step of these programs is to extend generalization of the desired response through reinforcing it in a variety of 
settings and with a variety of people. Unfortunately, none of these three programs provide measurement of generalization.

Kent (1972) added an interesting feature to his language training program. His program for severely retarded nonverbal children, basically follows the same steps as the previously mentioned programs but with the addition of play-group activities, in which the child has direct experience with the objects and actions he is learning to talk about during training. However, again it is unfortunate that no measurements of generalization are provided.

Gray and Ryan (1973) developed a language training program to teach the "nonlanguage" child, defined by them to be a child whose code sending is nonverbal, or if verbal, violates syntactic rules of usage. This program differs from the previously cited programs in that it assumes the child already has the ability to imitate strings of words. The program consists of forty-one sub-programs designed to teach a core of language structures. Operant procedures are used to teach the language structures. Gray and Ryan reported complete generalization of trained targets to spontaneous usage in the home. However, no data were reported to support this statement. Mulac and Tomlinson (1977) conducted a study using the Gray and Ryan program and found that the 
experimental group's use of the target in spontaneous speech was no better than the control group's. Gray and Ryan (1973) did report on improvements made by their subjects on the Northwestern Syntax Screening Test. However, whether these improvements were due to maturation or the program could not be established due to the lack of a control group.

Summary. The majority of research has been directed toward the development of operant training procedures for achieving the establishment of syntactical structures in response to pictures or objects within the clinic setting. That this goal has been attained is empirically supported in the literature (Guess et al., 1968; Hart and Risley, 1968; Schumaker and Sherman, 1970; Wheeler and Sulzer, 1970; Lutzher and Sherman, 1974; Martin, 1975). However, the end goal of language training is generalization of the clinically trained target to other settings and persons (Garcia and DeHaven, 1974). Although some studies and programs reviewed mentioned procedures to be used in obtaining generalization, only a few actually measured it (Hart and Risley, 1968; Gray and Ryan, 1973; Martin, 1975) and these studies had experimental design difficulties. Hart and Risley (1968) collected data in the treatment setting. Martin (1975) measured generalization in a different setting but with a structured task similar to that used in training, rather than measuring spontaneous 
speech. Gray and Ryan (1973) measured for generalization using spontaneous speech samples, but provided no data.

Whether or not operant language programs do achieve improved spontaneous language in their subjects has not been established due to a lack of attention towards measuring (Guess et al., 1978). However, several researchers have noted that generalization to spontaneous speech is a significant problem observed in clients trained with the use of operant language programs (Lee, 1974b; Mulac and Tomlinson, 1977; Guess et al., 1978; Rees, 1978). Mahoney and Seeley (1976) and McLean and Snyder-McLean (1978) suggest that traditional operant language programs may lack generalization results due to their concentration on the linguistic code and less attention directed towards semantics and pragmatics. A look at these more current theories of language acquisition may provide implications for obtaining generalization.

\section{CURRENT THEORIES OF LANGUAGE ACQUISITION}

\section{Semantic Theory}

The 1960's were dominated by Chomsky's theory of language acquisition; however, as researchers applied this theory to the study of children's early utterances, it was discovered to be inadequate in describing them (McLean and Snyder-McLean, 1978). Bloom (1970) noticed when she used grammatical rules (subject, verb and object) to describe 
children's utterances, she did not adequately reflect their knowledge of language. The utterance "mommy sock" would be described as "noun-noun", if one were applying grammatical rules. Bloom found that a much better description of an utterance could be obtained if the nonlinguistic context surrounding the use of the utterance was used to derive the child's meaning. If a child is holding up a sock to show to someone and is pointing to his mother saying "mommy sock", then the utterance may be described as possessive. On the other hand, if the child gives the sock to his mother and sticks out his foot while saying "mommy sock", the utterance could be more adequately described as agent-action.

Bloom's study generated an emphasis in research sometimes referred to as the "semantic revolution" (McLean and Snyder-McLean, 1978). Semantics refers to the relationship between the linguistic code and the nonlinguistic world of objects, people and events (Muma, 1978). Semanticists believe a child's early structures are determined by his intent to "mean" something, i.e., to express his knowledge of relationships between objects, people and events, as opposed to the structures being determined by innate grammatical rules (McLean and Snyder-McLean, 1978; Muma, 1978, Lucas, 1980). Therefore, the question of "what" a child learns when he acquires language can no longer be viewed in terms of structure alone. Semantics 
(meaning) and structure (code) are inseparable and both must be considered in the language acquisition process (Muma, 1978). Consideration of "meanings" and their matching structures directed researchers towards looking at new theories of "how" language is acquired.

The prevalent hypothesis states early language acquisition consists of learning how to map language on to concepts that have already been acquired on a nonlinguistic basis (Mahoney and Seeley, 1976; Bowerman, 1978; McLean and Snyder-McLean, 1978; Muma, 1978; Lucas, 1980). A closer look at this hypothesis reveals there are two interesting factors involved in language acquisition. There is the child forming nonlinguistic concepts and there is the adult language user providing linguistic labels for these concepts (Bruner, 1975; Leonard, 1975; Bowerman, 1978; MacDonald, 1978; Lucas, 1980). This theory suggests that language is acquired through the child's active participation in a dynamic partnership with the adult language users in his environment. A look at each partner's contribution to the process is appropriate.

Child. Researchers turned to Piaget's theory of early cognitive development as a means of explaining the concepts underlying the development of linguistic structures (Bowerman, 1978). Piaget believes children formulate schemas or concepts about their world through action and interaction with objects and people in their 
environment. Nelson (1974), in a study analyzing the first fifty words of eighteen subjects, found the one outstanding characteristic of early words is their reference to objects and events involved in dynamic relationships. Lucas (1980), also in agreement with Piaget, suggested that the child learns temporal concepts in relation to his interactions with objects, people and events in a variety of situations and that, these concepts are prerequisites to the use of verb inflections. For example, to use "going" instead of "go", the child would have to understand locative action. The child has another responsibility in addition to learning concepts, for if he wants to talk about his knowledge, he must learn the Iinguistic code from adult users.

Adult language user. Bruner (1975) points to the adult's role as being an interpreter of the child's intentions or meaning. He states that the early interaction patterns between the mother and the child form the basis of language acquisition. The adult attends to the child's interactions with his environment, interprets them and encodes them for the child (Bruner, 1975; Leonard, 1975; MacDonald, 1978; Lucas, 1980). The child learns to establish joint attention with the mother through increasingly sophisticated means, starting with such primitive functions as crying, bodily movement and eye contact. Gestures such as pointing and reaching may be used next. 
Eventually, the child uses linguistic devices to achieve his intentions. In summary, the adult's role in the acquisition process is to attend to the child's interactions with nonlinguistic elements, interpret his intended meaning and mark his meaning with conventional symbols. Researchers hypothesize that adult language directed toward children has some special features which aid the child in making a match between nonlinguistic interactions and the code.

Mahoney and Seely (1976) provide an excellent review of the literature concerning linguistic input. Speech directed toward young children has been found to be slower, with pauses between units of meaning. Mothers reduce the syntactical complexity of their speech so that it correlates with the child's level and also restrict their choice of vocabulary, choosing concrete labels to describe objects and events to their children. Speech directed to young children has been found to be repetitive, with the repetitions being paraphrases of one idea. The effects of these linguistic modifications are not clear; however, logically it appears, that such simplifications in the code make it easier for the child to comprehend the connection between his nonlinguistic interactions and the code used to refer to them.

Summary. The greatest contribution of the semantic revolution is its redefinition of "what" children learn 
when they acquire language and also "how" they develop language. Whereas previous theories, behavioral and transformational grammar, address the acquisition of the linguistic code, the semanticists address the acquisition of meaning underlying the linguistic code. On the question of "how" language is acquired, the behaviorists describe the child's role as passive. Importance is placed with the child interacting with the environment. The environment is seen to play the significant role. The transformational grammarians describe the acquisition process in terms of the child's innate ability to learn language. The child is seen as being cognitively active in the acquisition process and the role of the environment is not stressed. Semanticists view language acquisition as involving a dynamic partnership between the child and adult. This directs attention toward the use of language in social contexts.

\section{Pragmatic Theory}

Bates (1976) defines pragmatics as the rules governing the use of language in context, in other words, the use of language for communicating in a particular situation. The study of pragmatics has shifted attention away from the structural and semantic components of language towards an interest in the purpose of language, including both the global functions that language serves, such as providing a tool for communication, and the functions that 
individual utterances may serve, such as requesting information or demanding action. With the advent of pragmatics, speech-language pathologists have directed their attention toward communicative effectiveness or competency. Instead of examining only the structure and meaning underlying a client's utterance, they evaluate whether the utterance was successful in communicating the client's needs. In other words, did the client's listener understand the intent of the utterance? Can a child use an utterance to get what he wants, i.e., to regulate his listener's actions?

There are some language-handicapped children who, to become more effective communicators, need to learn the various functions of utterances, such as the greeting or regulatory functions. Such a child may not know that he can gain another person's attention by saying "Hi" (greeting) or that he can get something out of his reach by pointing to and labeling the object (regulatory) (McLean and Snyder-McLean, 1978). The child with a pragmatic disorder does not know how to use language to get what he wants.

In summary, the study of pragmatics has directed attention to the sometimes forgotten reason for language training, that is, the goal of improving communication. Communicative competency includes two factors, the knowledge of linguistic rules and the ability to apply these 
rules in appropriate contexts (Rees, 1978). Geller and Wollner (1976, as cited in Rees, 1978) provide an illustration of a child who has learned how to produce some structures but does not know when to use the structures to communicate:

After having been trained in the therapy room with the appropriate stimuli to ask "Who is it?" "What is it?" and "Where is it?" the clinician decided to test Jeffery's ability to use these questions in a more natural, real-life situation. Jeffery was told that he and the clinician were going for a walk, and he was reminded to ask questions when he got outside. At this point Jeffery opened the door, and announced to no one in particular, "Who is it?" "What is it?" "Where is it?"

\section{IMPLICATIONS FOR INTERVENTION}

Language programs traditionally have approached language as a set of sentences to be mastered independently of one's intent to code a particular idea for a particular purpose (Muma, 1978). In other words, aspects of communication have been separated out of communicative context. Syntax, semantics and pragmatics, however, are inseparable, i.e., linguistic forms (structure) are used to communicate ideas (semantics) with a particular purpose in mind (pragmatics) (McLean and Snyder-McLean, 1978). Language intervention programs based upon a broader, more comprehensive view of "what" language is and "how" it is acquired may produce better generalization results. Research in semantics and pragmatics has provided 
clinicians with a theoretical base that could be used for the development of new procedures for training language (Murna, 1978).

Current programs have proven their ability to teach children grammatical structures in response to pictures and objects. Unfortunately, children often do not use these structures in their spontaneous speech (Harris, 1975; Mahoney and Seely, 1976; Mulac and Tomlinson, 1977; Guess et al., 1978; McCormick and Elder, 1978). Perhaps they are not using the structures because they have no generalized meaning for them. Many researchers are recognizing the advantages of using natural contexts in training language (Hart and Risley, 1968; Holland, 1975; Martin, 1975; MacDonald, 1978; McLean and Snyder-McLean, 1978; Muma, 1978; Lucas, 1980; Miller, 1981). The term "natural context" seems to imply that no structure or preplanning is involved; suggesting perhaps, that the clinician simply brings in a pile of randomly selected toys and proceeds to interact with the client in an arbitrary manner. To the contrary, McLean and SnyderMcLean (1978) state that with concentration and effort the teacher can systematically develop an environment in which the communicative utterance can become highly controlled and predictable.

There are general guidelines suggested in the literature for planning both the context and the clinician's 
interaction patterns with the client in that context. Holland (1975) emphasizes the interrelatedness of word and activity for young children. In other words, children talk about what they and others are doing. This implies the need for using toys with which the child can manipulate and interact. Guess, Keogh and Sailor (1978) state that generalization is a function of the degree of similarity between training and natural settings. This implies that using toys from the child's environment or role playing familiar situations may promote generalization. Lucas (1980) and Muma (1978) suggest, in order for a child to formulate a concept, he must experience it in a variety of settings and usages. Harris (1975) reports that the more or larger variety of settings used in training, the greater the probability of generalization. In summary, the research seems to suggest that the planning of a wide variety of contexts would be beneficial in deciding on activities for training in natural contexts.

Hubbell (1977) provides clinicians with general guidelines to follow in planning their interactions with children when spontaneous talking is the goal, as would be the case when training language in natural contexts. He found that, generally, there is a negative correlation between spontaneous talking and commands, questions and expressions of approval or disapproval. Conditions associated with spontaneous talking were interactive 
patterns in which the mother followed the child's lead in activities and at the same time, conversed and commented on the child's focus of attention. It must be emphasized, that for this type of interaction pattern to be successful in language training, the clinician must structure the environment so that the "child's lead" predictably results in the occurrence of the target structure.

There appears to be a trend toward viewing the clinician's role in teaching language within natural contexts, as being one in which he functions as a facilitator, expander and idealizer of the child's utterances (Bruner, 1975; Muma, 1978; Lucas, 1980; Miller, 1981). In the literature on facilitation of language within natural contexts, the terms modeling and expansion are frequently mentioned. Miller (1981) refers to modeling as providing the appropriate language structures to describe the child's activities when he is doing little talking. Muma (1978) calls this parallel talking i.e., using well-formed sentences to describe the adult's and child's activities.

The literature provides different terms to describe the adult's response to a child's talking. The term expansion refers to when the adult responds to a child's incomplete utterance, such as "Mommy eat lunch" with a well-formed sentence which preserves the child's meaning, such as "Mommy is eating lunch." Muma (1978) states that 
sometimes adults respond to a child's utterance with a simple, but nonexpanded utterance which broadens the communicative context but maintains the child's utterance as the focus. For example, if the child says: "Doggie bark," the adult may respond, "The doggie's hurt." Muma calls this the simple expiation model and suggests it is a useful syntactic technique for learning basic sentence structure and possibly simple transformations. The literature on the effects of modeling and expansions on syntactical development is inconclusive (Cazden, 1965 as cited in Dale, 1976). However, Muma (1978), Lucas (1980) and Miller (1981) all recommend using these interactive patterns because they provide correct structures to match the meaning of a child's utterance.

McLean and Snyder-McLean (1978), MacDonald (1978) and Miller (1981) appear to agree that social-play interactions between teachers and children provide an excellent natural context for language training. McLean and SnyderMcLean speculate on the reason why language intervention programs use natural contexts so sparingly, if at all. They state that the opinion is strong that handicapped children are not normal and, therefore, "normal" language teaching methods would not be powerful enough to provide the compensatory help needed. According to McLean and Snyder-McLean (1978), this is a valid view, but not reason enough to conclude that nothing in the normal process 
would be helpful in planning intervention.

Some scholars acknowledge the validity of using both structured training and training in natural contexts (Hart and Risley, 1968; Hubbel1, 1977; MacDonald, 1978; McCormick and Elder, 1978). Hubbell (1977) reports implementing structured work in individual clinical sessions in standard clinic room and facilitative work, i.e., use of natural context, in a small nursery school situation. His reported preliminary results suggest this combined approach may be very effective with many language delayed children. He reasons that the structured training provides practice with linguistic structure and the use of facilitation or natural contexts provides the interpersonal aspect.

MacDonald (1978) developed the Environmental Language Inventory (ELI), which is not a written language training program, but rather, is a set of general guidelines that can be adapted for different individual's remedial needs. The ELI is based upon the hypothesis that language rules need to be taught involving the client's natural environment. The training, design provides for establishment of rules in imitation and simultaneous generalization of the rules into conversation and more spontaneous use in play. The ELI's paralleled imitative and conversational procedure is referred to as the Conversation-Imitation-Conversation (CIC) model. An example of the CIC model for teaching the semantic rule, "Action + Object" follows: 


\section{Clinician Behaviors}

1. Nonlinguistic cue: Kicks ball in air

2. Conversation cue: "What am I doing?"

3. Imitation due: "Say, kick ball"

4. Nonlinguistic cue: Again kicks ball in air

5. Conversation cue: "What am I doing?"

Structured play activities follow the CIC procedure. During the play period, the child is required to use those rules trained with the CIC procedures.

This author recognizes the possible advantages proposed by Hubbell (1977) and MacDonald (1978) of using both structured training and training in natural context simultaneously to teach syntactical structures to language delayed children. Yet, a review of the literature by this investigator found no study comparing a method employing simultaneous or parallel use of structured training and training in natural contexts, to the more traditional linear method of first establishing the structure and then, as the final step attempting to generalize the established structure to natural contexts. Perhaps a method using both structured training and natural contexts from the beginning of remediation would produce better generalization results than a method which waits until the end of the program to undertake generalization. The purpose of this study was to compare the generalization results of two such methods. 


\section{CHAPTER III}

\section{METHODS AND PROCEDURES}

This chapter describes the general plan of the study, followed by a detailed description of methods and procedures.

\section{GENERAL PLAN}

This investigation was conducted at Portland State University Speech and Hearing Clinic during April and May, 1981. Six subjects, ranging in age from 4 years 7 months to 5 years 10 months were selected. All subjects demonstrated normal hearing, normal receptive language abilities and delayed expressive language abilities. Each subject was matched with another subject according to Mean Length of Utterance and omission of a particular grammatical rule in his expressive speech. Three pairs of subjects were matched and one of each pair was randomly placed in one of the two intervention groups. One subject of each matched pair was presented a particular syntactical structure using the Monterey Language Program (Method A), while the other subject of the matched pair was presented the same syntactical structure using the Monterey Language Program during the first half of the 
session and the natural use of the structure in a play situation during the second half of the session (Method B). Intervention consisted of three twenty-five minute sessions a week, for twelve sessions. A criterion test devised to measure generalization, was administered before intervention, three times during intervention and one week following intervention. The generalization results of each method were compared using descriptive analysis of the data to answer the four questions posed for this study.

\section{SUBJECTS}

Six subjects, five males and one female, ranging in age from 4 years 7 months to 5 years 10 months were selected from children who previously had attended or had been evaluated at the Portland State University Speech and Hearing Clinic. A three-step procedure was used to select the subjects: 1) case files of clients at Portland state University were reviewed; 2) potential subjects were screened; and 3) children who could be matched on predetermined variables were selected as subjects for the study.

Review of Case Files

This investigator reviewed case files of children enrolled in Articulation and Language Clinic Winter, 1981, and of children waiting to be served during summer, 1981 . Children meeting the following criterion were considered 
to be potential subjects: 1) chronological age between 4 years 6 months and 6 years; 2) demonstrated normal hearing; 3) had approximately age level receptive language scores; 4) exhibited delayed expressive language scores; and 5) demonstrated at least 70 percent intelligibility in known contexts. The parents of potential subjects were contacted by telephone and after the study was explained were asked if they would be interested in their child being screened for participation in the study. If they were interested, a permission form allowing for administration of the screening tests, was signed (Appendix A).

Variables Screened and Instrumentation Used

Auditory Acuity. Normal hearing was defined as passing an audiometric screening at $20 \mathrm{~dB}$ for the frequencies of $500 \mathrm{~Hz}, 1000 \mathrm{~Hz}$ and $2000 \mathrm{~Hz}$ in both ears. Hearing screening was performed in a quiet, carpeted clinic room with a portable Beltone audiometer, ANSI, 1969.

Receptive Language Abilities. For the purposes of this study, normal or slightly above normal was defined as a Mental Age (M.A.) for receptive vocabulary on the Peabody Picture Vocabulary Test (Dunn, 1965) which deviated no more than 6 months below or 12 months above the child's chronological age. According to Emmerick and Hatten (1974), the PPVT is one of the best screening measures of language with regard to standardization, population, and reliability studies. 
Expressive Language Abilities. A 75-utterance language sample was obtained from potential subjects who previously had passed the hearing screening and were within the specified limits on the PPVT. The initial purpose of the sample was to note whether a child omitted or incorrectly used syntactical structures in his spontaneous speech and whether his speech appeared to be at least 70 percent intelligible in context.

Procedures suggested by Lee (1974a) were used to gather the utterances from each child. Using a clinic room as the setting, the investigator and potential subject played with toys. A cassette tape recorder was used to record the samples. If it was noted during the language sampling procedure that the child omitted or incorrectly used syntactical structures and appeared to be at least 70 percent intelligible in context, he remained a possible candidate and his language sample was further examined through the use of two calculations, Mean Length of Utterance (MLU) and Speech Intelligibility Index (SII).

MLU is defined as the average length of a child's utterances in morphemes (Dale, 1976). It is an index which provides an estimate of a child's expressive language development in relationship to his peers. In determining MLU's for this study, the first 25 utterances of a sample were discarded and the remaining 50 used for calculation, following the rules designated by Dale 
(1976). The purpose of obtaining MLU's was to provide an index to be used in matching subjects according to expressive language abilities.

Speech intelligibility for each child was determined from the 50-utterance language sample. The number of unintelligible utterances was subtracted from the total 50 utterances, thereby resulting in the number of intelligible utterances, which was translated into an intelligibility percentage. In this study, the intelligibility percentage is referred to as the speech Intelligibility Index (SII). A SII of at least 70 percent was necessary to remain a possible subject, in order, to insure enough understanding of a child's speech to determine whether or not he used the syntactical structure in his spontaneous speech.

Selecting Subjects with Matched Abilities

The investigator reviewed the screening information gathered from potential subjects who met the five criteria described above. Six subjects were selected based upon the investigator's ability to form three pairs matched according to two criteria: 1) MLU matched within .5 of a morpheme and 2) incorrect usage of the same syntactical structure in spontaneous speech. The final criterion that all six matched potential subjects had to meet was demonstrating the presence of an articulatory marker for the chosen syntactical structure. The photo Articulation 
Test (PAT) (Pendergast, Dickey, Selmar and Soder, 1965) was administered for that purpose. All six potential subjects met the final criterion, and after permission forms (Appendix B and Appendix C) were signed, became the designated subjects of this study. Table I illustrates how the subjects were paired. See Appendix $D$ for more complete descriptions of the subjects.

TABLE I

MATCHING OF SUBJECTS ON MEAN LENGTH OF UTTERANCE (MLU) AND ERRORED STRUCTURE*

Subject Method Pair MLU Error structure

$\begin{array}{lllll}\text { Subject } & \text { A } & 1 & 4.54 & \text { them/they } \\ \text { Subject } & \text { B } & 1 & 4.56 & \text { them/they } \\ \text { Subject } & \text { A } & 2 & 4.34 & \text { her/she } \\ \text { Subject } & \text { B } & 2 & 4.28 & \text { her/she } \\ \text { Subject } & \text { A } & 3 & 5.14 & \text { her/she } \\ \text { Subject } & \text { B } & 3 & 5.18 & \text { her/she }\end{array}$

*Method $A$ was the Monterey Language Program and Method $B$ was the Monterey Language Program used during the first half of each session and play activities the second half

PROGRAM DESCRIPTIONS

Monterey Language Program (MLP), Method A

Content. The MLP is a program designed to teach grammar, defined by Gray and Ryan (1973) as a basic set of 
rules which permits the user to generate sentences. According to Gray and Ryan, the rules or structures included in the MLP were chosen because they can be used to develop complex sentences and can also lead to several other forms of sentences. Appendix $\mathrm{E}$ shows the sequence of forms taught in the forty-one programs of the MLP.

Placement. According to Gray and Ryan (1973), the use of the MLP is considered, if after asking parents and teachers about a child's talking and observing a small sample of his speech, the child is determined to have an oral grammatical-syntactical deficit. The Programmed Conditioning for Language Test (PCLT), a test which measures the child's usage of grammatical structures taught in the MLP, is administered in order to decide whether any of the MLP language programs would be useful. Specific grammatical errors on the PCLT indicate the need for specific programs. The child is started on the first failed program. A criterion test, to be used as a pre and post measure, is given for the specific target to be taught (Appendix F). The manual provides placement procedures to determine the exact starting point in a specific program for a particular child.

For the purpose of this study, slight deviations were made in the placement procedures described above. The PCLT was administered to all six subjects. However, the first failed programs were not chosen as a starting 
place. Instead, because of the need to match subjects, the programs corresponding to their errored structure shown in Table I were used. Unexpectedly, only four of the subjects failed the PCLT test item corresponding to their chosen errored structure in conversational speech as shown on Table I. Two subjects, Subject A2 and B2, passed the test item corresponding to their errored structures in conversational speech. However, all six subjects received scores of 0 percent on their respective criterion tests. Criterion test scores are used in the MLP to determine whether or not a child needs a program. Therefore, it was decided, that for the purposes of this study, the programs were appropriate for all six subjects, regardless of their PCLT responses. All subjects started with the first step of their respective programs which is a common practice for children who have never been trained with the MLP.

Procedures. The MLP's method of teaching syntactical forms is based upon two concepts, learning theory and programming. Gray and Ryan (1973) refer to learning as a conditioning process viewed in terms of Stimulus-Response-Consequence. The consequence of a response either increases or decreases the frequency of that response in the future. These authors define teaching as controlling the stimuli and the consequences in order to change the response. Programming can be defined as sequencing the learning tasks in small steps 
from easier to more difficult levels of response complexity.

The actual procedures used in teaching a specific program are referred to as the "delivery system" (Gray and Ryan, 1973). The teaching variables include the stimulus, model, response, reinforcer, reinforcement schedule and criterion. Appendix $G$ describes each variable briefly and Appendix $\mathrm{H}$ includes a copy of one of the two programs administered in this study. One is entitled: He, She, It. Only the series teaching "She" were administered. The other program is entitled: You, They, We and, likewise, only the series teaching "They" were used.

When a program was completed, i.e., when the child met criterion for the last step of the program (structured conversation), a home carry over program was initiated. For the purposes of this study, the home carry over program was initiated at the beginning of the story series, the second to the last series of the program (See Appendix H). This procedure is recommended by the Certified Monterey User's training notes. The parent was given a form with instructions on what to do with the child. Basically, the parent was required to employ the same format used in the last steps of the program, that is, to present a picture and ask questions specifically designed to elicit the target structure. A score sheet was provided, on which they recorded the correctness of 
the responses. The parent "worked" with his child from five to ten minutes a day for eight days within a two-week period.

Monterey Language Program/Natural Context, Method B

In Method B, the MLP was used in the first half of each session. The MLP format was followed precisely as it was in Method A, with the exception of the length of time. Therefore, a child trained in Method $B$ experienced the exact procedures and materials as did his matched pair in Method A, for the first half of each session. In the second half of each session, Method B subjects participated in play activities.

General Guidelines used in Planning Play Activities.

The play activities were planned with consideration of two factors, i.e., the target structure involved and the interests of the client. Based upon information supplied by the mothers of each subject's favorite toys and activities, the investigator planned a variety of play activities which had a high probability of eliciting the target structure spontaneously. Even though the play activities varied, interaction patterns or ways of responding to the subjects were the same. The following interaction patterns are described in Appendix I: tangential play, cooperative play, role playing, games, modeling, expansion and elicited imitation. 
Investigator's Training in the MLP

This investigator was initially trained in the MLP while functioning as a part-time aide in a Communication Disorders Class at the Eugene Hearing and Speech Center, Eugene, Oregon (1975-1977). The training speech-language pathologist was a Certified Monterey User. For the purposes of this study, four years later, the investigator engaged in a three-step training plan. First, the investigator read the book, A Language Program for the Nonlanguage Child by Gray and Ryan (1973) and also, the MLP manual. Secondly, the investigator participated in two one-hour training sessions with a Portland state University clinical supervisor who holds the certificate of clinical competence and who is a Certified Monterey User. She played the role of a child and tested the investigator's knowledge of placement procedures and program delivery procedures. The trainer judged this investigator to be proficient in conducting the MLP. Lastly, the investigator practiced the MLP with normal children from a local daycare facility. The programs "She" and "They" were selected for practice, as they were the ones to be administered in the study.

\section{CRITERION TEST}

Purpose. This study sought to assess subjects' generalization of the trained syntactical target to 
spontaneous speech. Therefore, a criterion test with tasks ranging in spontaneity, was designed by the investigator, to provide a sensitive measurement of this variable.

Description. This test, which paralleled one designed and used by Mulac and Tomlinson (1977) consisted of five language evocation tasks ranging along a continuum for spontaneity of utterance, from spontaneous utterances in free play to immediate imitation of sentences by the tester. The purpose of TASK 1 (spontaneous utterances), the first task administered, was to obtain a sample of a subject's spontaneous speech, in order to determine whether generalization had occurred. Toys were used as stimuli and the subject and tester interacted as they would in any language sampling procedures. After two subjects did not emit the trained structure (correctly or incorrectly) during Criterion Test 1 , great care was used in the succeeding testings to select toys which would have a high probability of eliciting the trained structures. For example, several cars were used rather than just one, in order to elicit "they". Each pair of subjects was exposed to the same toys during a particular testing and toys varied from testing to testing. Toys used during intervention with Method B subjects were not used for testing.

During administration of TASK 2 (relatively 
spontaneous), the tester directed the subject's attention toward a picture within a storybook, on a sequence card or on a poster, that had high probability of spontaneously eliciting the target structure. The same stipulations as those described above in choosing toys, were used in choosing material for this task.

TASK 3 (model) added more structure to the testing situation. The tester held up a picture and modeled a sentence using the target structure correctly, and then repeated this procedure with another picture. Next, ten unmodeled pictures were individually presented to the subject and he was directed to tell about the picture. Pictures were changed for each testing and were not ones used previously in intervention.

TASK 4 (questions) involved even more structure and modeling of the target. Ten pictures were presented individually and a question with the target structure within it, was asked. For example, if the target was "she", then a question such as, "What is she doing?" was presented. TASK 4 follows the same procedures used in the MLP's criterion tests, with the exception that in this study, ten presentations were used, rather than five.

TASK 5 (imitation) was the most structured of all the tasks and merely required a subject to imitate a sentence containing the target structure when presented with a picture. The sentences were approximately the same 
length, usually including a noun, verb, preposition and an object. As in the previous two tasks, ten pictures were presented.

Administration. The pre-criterion test was administered by this investigator in a clinic room prior to the first intervention session. Administration required forty to fifty minutes. Criterion tests $1,2,3$ and post-test were administered by three trained undergraduate speech-language pathology students. One tester was assigned to a pair of subjects.

Criterion test 1 was administered after six intervention sessions, criterion test 2 after nine intervention sessions, criterion test 3 after twelve intervention sessions and the post-criterion test was administered one week after the last intervention session.

Tester's Training. The investigator briefly explained the purpose of the testing as providing information about the results of different syntax intervention methods. Each tester was individually trained by this investigator in a two-hour training session. The procedures used for administration of the five tasks were simple and welldefined, and, therefore, were easily learned by all three testers. Recording and scoring of the subjects' responses was the responsibility of the investigator.

Recording and Scoring. The investigator observed testings through a one-way mirror and recorded the 
subjects' responses on a criterion test form (Appendix J). Each testing was tape recorded so that the investigator could verify her recorded responses. Procedures for all testing sessions were alike, with the exception of criterion test 1 with subject $A 3$, in which the investigator sat in the clinic room with the subject and tester, as no clinic room with a one-way mirror was available.

The score for each task represented the percentage of target utterances used correctly. For TASK 1 , the investigator recorded all utterances in which the target structure occurred, both correctly and incorrectly, during fifteen minutes of play. For example, during a play period, a subject may have used the structure eleven times, seven times correctly ("She my doll!", "She running home.", "Where she go?", etcetera) and four times incorrectly ("her fall down!", "Don't know where her going.", etcetera). In this example, the TASK I score would be 64 percent.

The TASK 2 score was obtained by recording the first ten utterances containing the target structure. The percentage of utterances used correctly was easily computed. For example, if a subject used the structure correctly in four out of ten utterances, his score would be 40 percent.

In TASKS 3,4 and 5 , the stimuli consisted of ten pictures. Therefore, the scores of these tasks were 
derived in the same manner as TASK 2 scores, i.e., the number of utterances in which the target was correctly used was translated into a percentage of correct usage.

\section{PROCEDURES}

The six subjects were matched on the basis of previously described variables and randomly assigned to one of the two intervention methods: Method A, Monterey Language Program, or Method B, Monterey Language Program/Natural Context.

Remediation of all subjects was conducted by this investigator in a clinic room at Portland State University Speech and Hearing Clinic. Subjects were treated individually in three twenty-five minute sessions per week until the Method A subject of each pair completed his respective MLP program. A subject was determined to have completed a program when a parent had finished the home carry over phase and when the subject passed the MLP criterion test for his program.

Subjects in Method A were taught using the MLP. Procedures were followed as indicated in the program. Method B subjects were taught using the MLP in the first half of each session and participation in play activities in the last half. Refer to Appendix $K$ for descriptions of play activities and Table I for the syntactical structures taught to each matched pair. 
All three Method A subjects completed their programs in the same number of sessions, that being a total of twelve sessions, or five hours of training. In addition, Method A subjects completed the home carry over phase, which involved approximately five to ten minutes of homework a day, for eight days within a two week period. Therefore, Method A subjects received approximately one additional hour of training as compared with Method $B$ subjects .

The criterion test was administered by this investigator before starting intervention and was readministered by three trained undergraduate speech-language pathology students according to the schedule described earlier in this paper.

DATA ANALYSIS

A descriptive analysis of the data was performed. Tables and graphs were used to display visually the results. 
CHAPTER IV

RESULTS AND DISCUSSION

RESULTS

The purpose of this study was to answer four questions pertaining to the generalization of a clinically trained syntactical structure to spontaneous speech. Three subjects received individualized instruction of a target structure with the Monterey Language Program (MLP) (Method A). The other three subjects received individualized instruction of a target structure with the MLP in the first half of each session and structured play activities in the second half (Method B). A criterion test, comprised of five tasks ranging in spontaneity from spontaneous utterances during play (TASK 1) to elicited imitation (TASK 5), was administered before intervention, three times during intervention and one week following the last intervention session. The answers to the four questions posed in this study were obtained by analyzing the results of those testings.

The first question posed was: Will children taught with a traditional syntax program evidence generalization of the trained syntactical structure to spontaneous speech? The pre-criterion test results and the post-criterion test 
results of Method A subjects are illustrated in Table II. The most relevant section of Table II is the section comparing pre and post-test scores on TASK 1 . The precriterion test TASK 1 score represents the percentage of utterances in which a subject used the target structure correctly while engaged in free play with this investigator, prior to intervention. The post-criterion test TASK 1 score represents the percentage of utterances in which a subject used the target structure correctly while engaged in free play with a tester other than the investigator, following intervention.

On TASK 1 of the pre-test, Subject Al used the target structure correctly 0 percent of the time; whereas, in the post-test of TASK 1 , he used it correctly 100 percent of the time. Subject Al, thus, generalized the target structure to his spontaneous speech during play.

Subject A2 did not generalize the target structure to his spontaneous speech during play, as is evidenced by pre and post-test scores of 0 percent. However, on post-test TASKS 3, 4 and 5, Subject A2 scored 100 percent as compared to pre-test TASKS 3,4 and 5 scores of 10 percent, 0 percent and 70 percent, respectively. His post-test TASK 2 score was 70 percent, as compared to a pre-test TASK 2 score of 0 percent. In summary, at the time of post testing, Subject A2 produced the target structure correctly with high proficiency in structured settings 


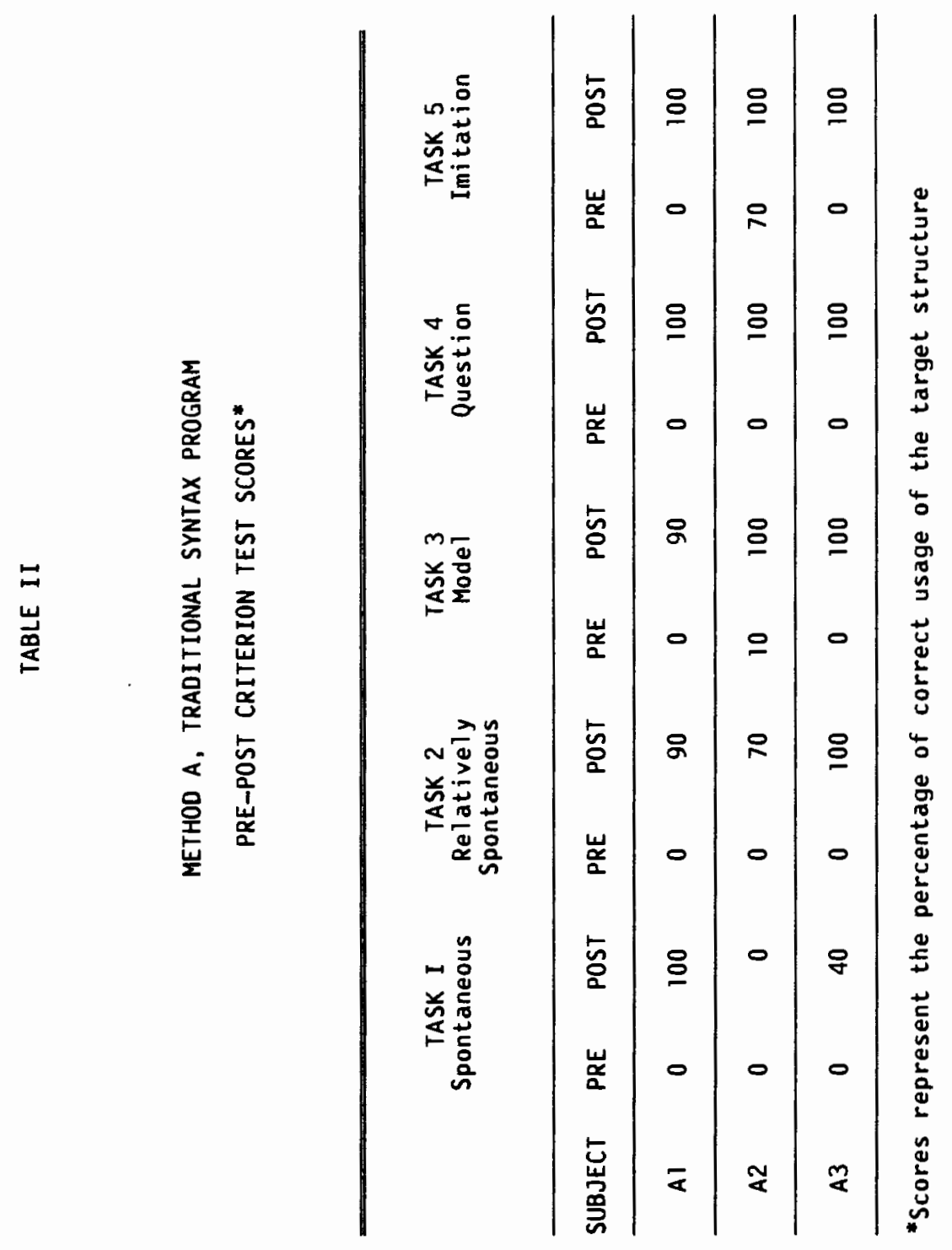


(TASKS 3,4 and 5), but as the setting became more natural, his proficienty decreased from 70 percent in a semistructured setting to 0 percent in an unstructured, natural setting.

Subject A3 received a pre-test TASK 1 score of 0 percent and a post-test TASK 1 score of 40 percent. According to Brown (1973, as cited in Dale, 1976), who suggests that a child has acquired a syntactical structure when he uses it correctly in at least 90 percent of the obligatory contexts during spontaneous speech, subject A3 has not yet acquired the target structure. His post-test scores of 100 percent on TASKS 2, 3, 4 and 5 would seem to indicate that the target structure is firmly established in structured and semi-structured settings. In conclusion, after completing a traditional syntax program, one subject generalized the target to his spontaneous speech, another subject had begun to generalize the target structure to his spontaneous speech and the last subject failed to generalize the target structure to his spontaneous speech.

The second question posed was: Will children taught with a traditional syntax program in combination with nontraditional methods (play activities) concurrently, evidence generalization of the target structure to spontaneous speech? A comparison of pre-criterion test results and post-criterion test results of Method $B$ subjects is illustrated in Table III. Subjects Bl and B2 


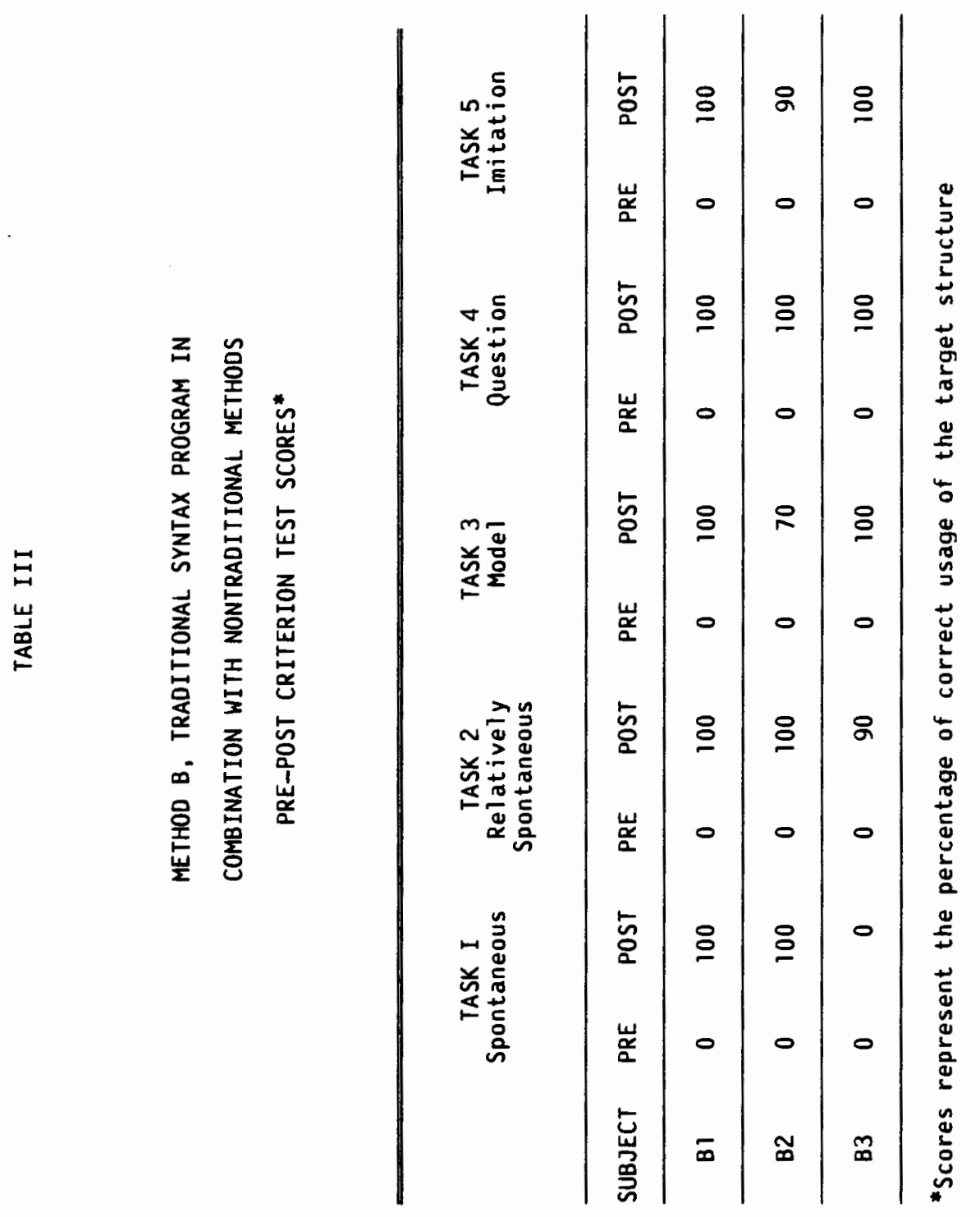


received a pre-test TASK 1 score of 0 percent and a post-test TASK 1 score of 100 percent, indicating that they used the target structure correctly 0 percent of the time in their spontaneous speech prior to intervention and following intervention, they used the target structure correctly 100 percent of the time in spontaneous speech. Subject B3 failed to generalize the target structure to her spontaneous speech, as is evidenced by a post-test TASK 1 score of 0 percent. However, her post-test TASK 2 score of 90 percent indicates she used the target structure correctly without modeling in relatively spontaneous settings. Thus, after receiving training with a traditional syntax program in the first half of each session and structured play activities in the second half of each session, two subjects generalized the target structure to spontaneous speech. The other subject did not generalize the target to spontaneous speech, but did use it with high proficiency in a relatively spontaneous setting.

The third question posed was: Will children taught with a traditional syntax program in combination with nontraditional methods (Method B) evidence greater, lesser or the same generalization of the target syntactical structure as children taught with a traditional syntax program (Method $A$ )? In order to answer this question, post-criterion test results of each pair were compared. Figure I illustrates post-criterion test results of 
Pair $I$, Subject $A l$ and $B l$. Following intervention, both Subjects $A I$ and $B I$ used the target structure correctly 100 percent of the time in their spontaneous speech and not surprisingly, also used it correctly in the more structured TASKS $2,3,4$ and 5 .

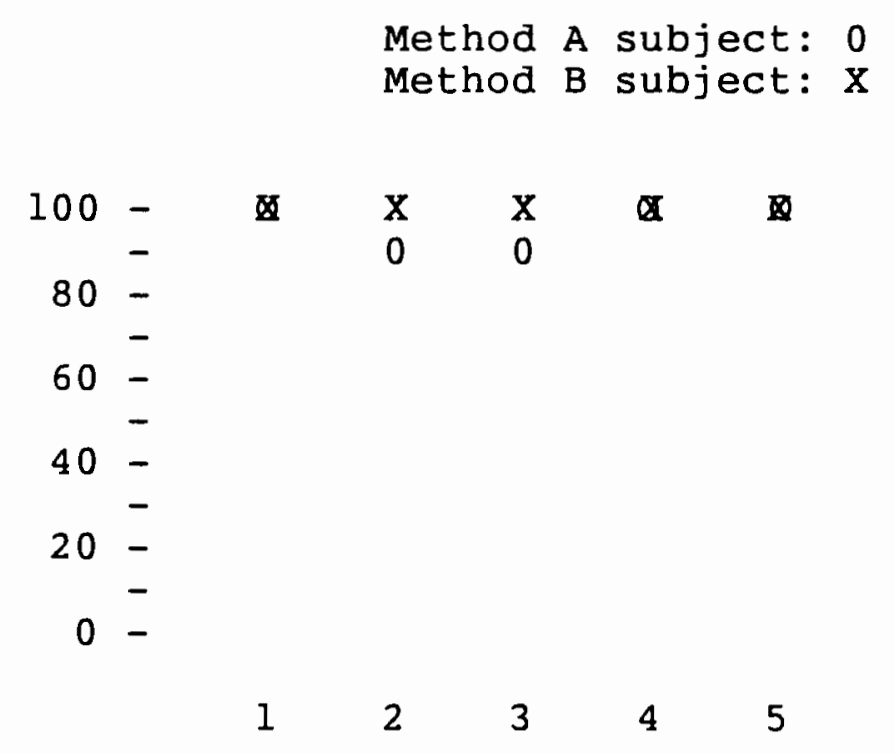

TASKS

Figure 1. Post-Criterion Test Scores for Pair 1.

Figure 2 illustrates post-criterion test results of Pair 2, Subject A2 and subject B2. Subject A2 failed to use the target structure correctly in his spontaneous speech (TASK 1), used it inconsistently in a relatively spontaneous setting (TASK 2) and produced it correctly 100 percent of the time in structured settings (TASKS 3,4 and 5). Contrastingly, his matched pair, subject B2, used the target structure correctly 100 percent of the time in his spontaneous speech and predictably performed well on 
more structured tasks. His lower TASK 3 score was due to his use of incomplete sentences, such as, "walked home" instead of "She walked home.", rather than using "Her" for "She".

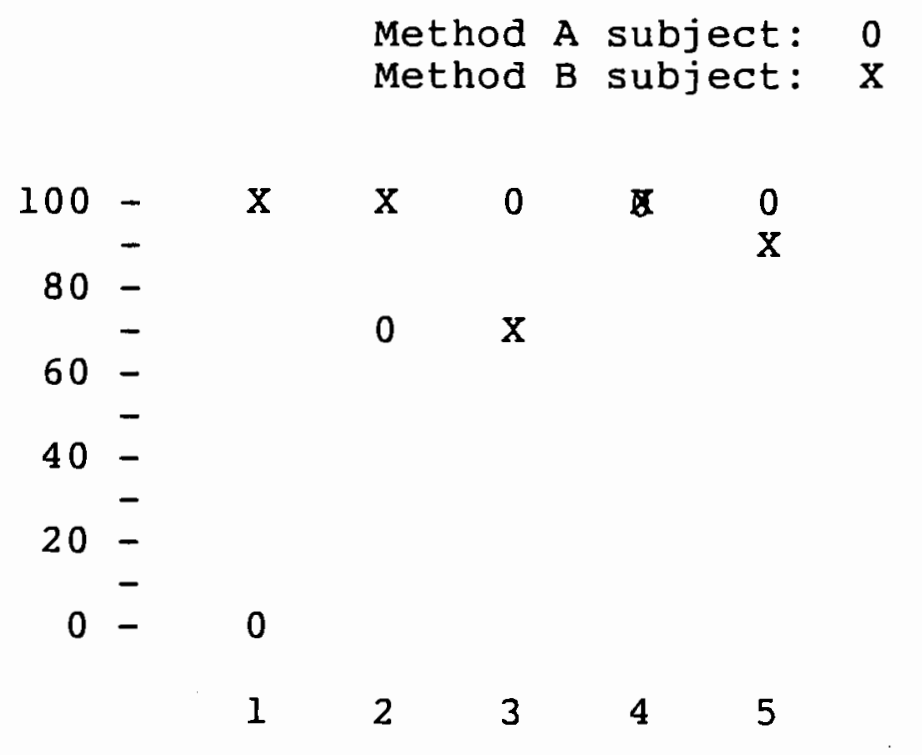

TASKS

Figure 2. Post-Criterion Test Scores for Pair 2.

Figure 3 illustrates post-criterion test results of Pair 3, Subject A3 and Subject B3. Following intervention, subject $A 3$ produced the target structure inconsistently (40 percent) in his spontaneous speech (TASK 1), although performing perfectly in a relatively spontaneous setting (TASK 2) and in structured settings (TASKS 3, 4 and 5). His matched pair, Subject B3 failed to use the target structure correctly in her spontaneous speech (TASK 1) and yet, like subject A3, used it with high proficiency in both relatively spontaneous settings 
and structured settings.

In summary, the answer to the third question differs depending upon the pair examined. In pair 1, the child taught with Method B evidenced the same generalization of the target structure as did his matched pair taught with Method A. In Pair 2, the child taught with Method B evidenced greatly superior generalization of the target structure then his matched pair. In Pair 3, the child taught with Method B evidenced somewhat lesser generalization of the target structure than her matched pair.

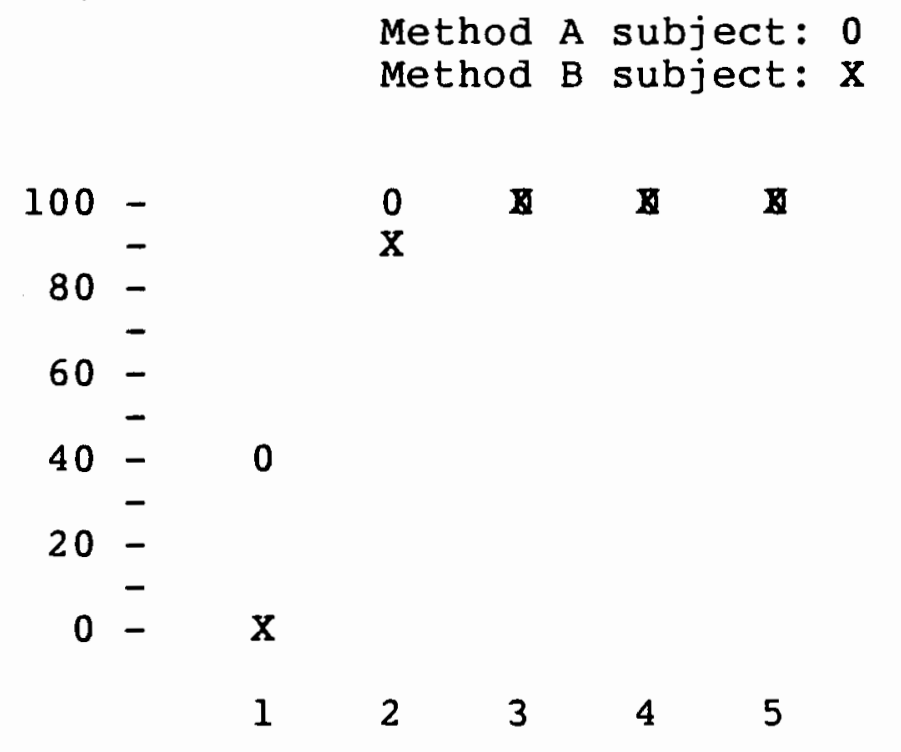

TASKS

Figure 3. Post-Criterion Test Scores for Pair 3.

A different way of answering the third question would be to compare the two groups as wholes. Figure 4 illustrates that, of the three subjects trained with Method $B$, 
two generalized the structure to spontaneous speech; whereas of the three subjects trained with Method A, one generalized the structure to spontaneous speech, while another demonstrated inconsistent generalization. Both methods produced one subject each, Subject A2 and Subject B3, who failed to generalize the target structure to spontaneous speech.

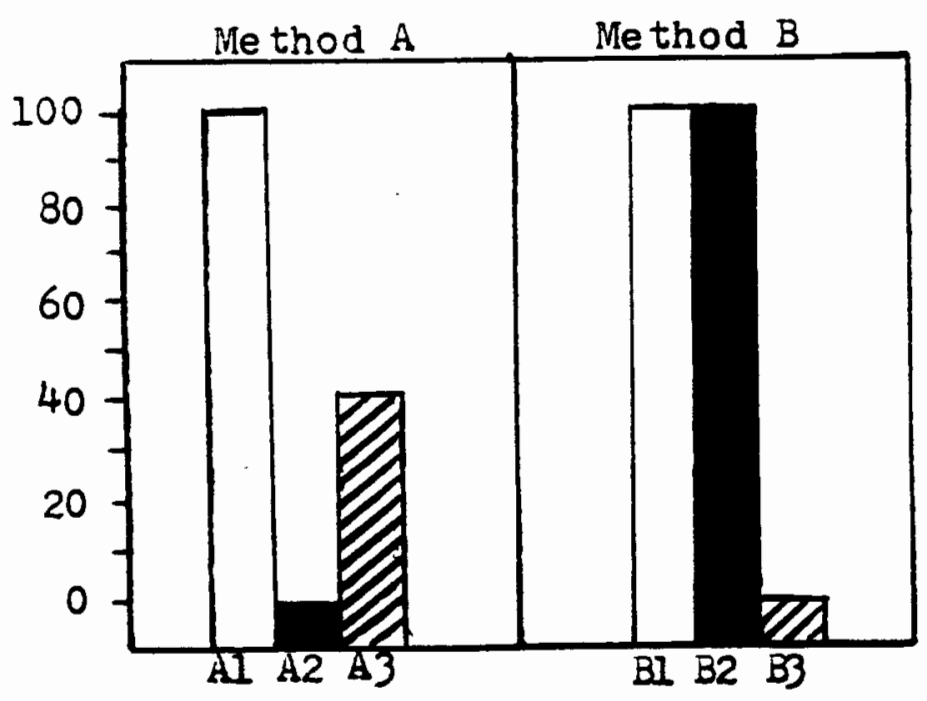

SUBJECTS

Fiqure 4. Post-Criterion Test Task 1 Scores for Method A and Method B Subjects.

Figure 5 compares subject $A 2$ 's and Subject B3's post-test scores on five tasks. Even though, they both failed to use the target structure correctly in a spontaneous play setting (TASK I), Subject B3 evidenced slightly greater generalization of the target structure to a relatively 
spontaneous setting than did Subject A2. In conclusion, after comparing the two groups' performances, it appears that the group trained with a traditional syntax program in combination with nontraditional methods as a whole, evidenced slightly better generalization of the target structure than the group trained with a traditional syntax program.

Method A subject: 0

Method B subject: X

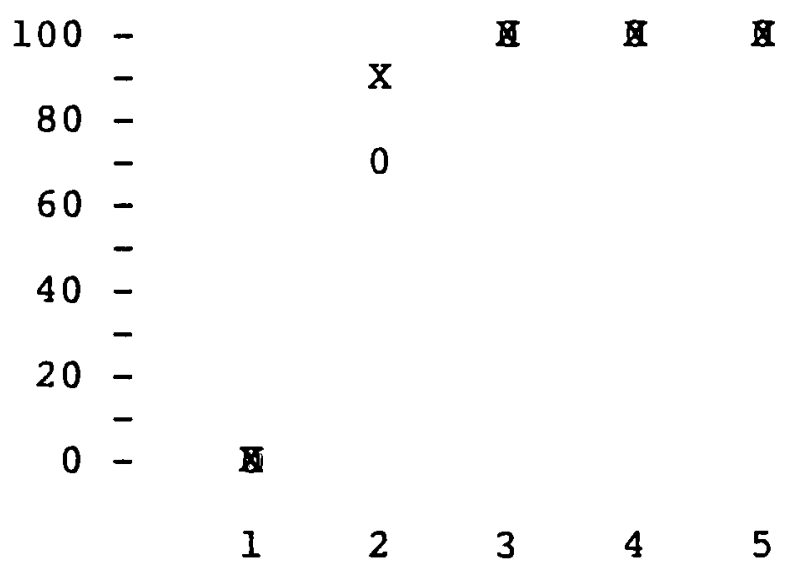

TASKS

Figure 5. Post-Criterion Test Scores for Subject A2 and Subject B3

The fourth question posed for this study was: If children in both groups evidence generalization of the target structure to spontaneous speech, will children taught with a traditional syntax program in combination with nontraditional methods (Method B) take fewer, the same or greater number of sessions than the children 
taught with a traditional syntax program (Method A)? As four subjects, two from each method, demonstrated some degree of generalization, TASK 1 testings for these subjects were compared to determine which ones took less time to generalize, i.e., those trained with Method $A$ or those trained with Method B. Figure 6 illustrates the four subjects' generalization of the target structure to spontaneous speech after six intervention sessions (criterion test 1), nine intervention sessions (criterion test 2) and twelve intervention sessions (criterion test 3 ).

Subject $A I$,

Subject $A 3$ :

Subject $B 1: \square$

Subject B2:
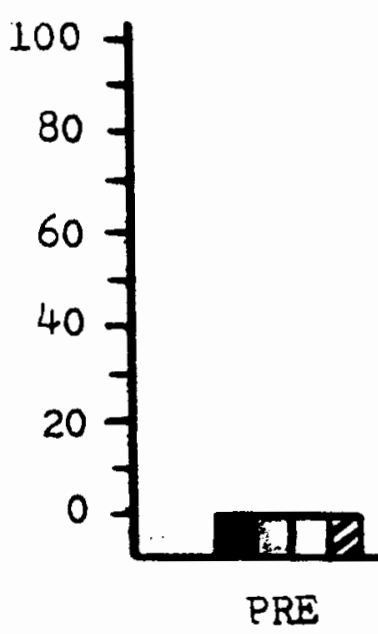

PRE

Figure 6. Subject $A 1, A 3, B 1$ and $B 2$ 's Scores on TASK 1 For Pre-Criterion Test, Criterion Test 1, Criterion Test 2, Criterion Test 3 and Post-Criterion Test. *No scores were obtained for subject $A l$ and $B l$, as the target did not occur during the play period.

All four subjects received a pre-test TASK 1 score of 
0 percent, indicating that none of them used the target structure correctly in their spontaneous speech prior to intervention. Criterion test 1 TASK 1 scores need some explanation. Subject $A 1$ and $B 1$ received no scores, as during the fifteen minute play period, the target structure did not occur, either correctly or incorrectly. Likewise, Subject $B 2$ used the target structure only once (incorrectly), providing an extremely small sample of his ability. Subject A3's drop in scores from his test 1 score of 77 percent to his test 2 score of 22 percent needs some inspection. This investigator believes the test 1 TASK 1 score was an invalid sample of subject A3's spontaneous speech, as the testing conditions were different for this test. For subject A3's test 1 only, the investigator recorded responses in the testing room, as no rooms with one-way mirrors were available. The premise that subject $A 3$ 's awareness of the investigator elevated his test 1 score can be supported by two facts. First of all, his test 1 TASK 2 score was poorer (40 percent) than his test 1 TASK 1 score (77 percent). Yet, theoretically TASK 2 should be easier than TASK 1, as more structure is involved. It is suggested that during the initial stages of test 1 , i.e., during the TASK 1 play period, subject $A 3$ was very aware of the investigator, but then as testing progressed on to TASK 2, he forgot about her and started responding more "normally." Secondly, 
with the investigator not in the testing room for test 2 TASK 1, Subject A3's scores decreased to 22 percent. To summarize, it is unfortunate that criterion test TASK 1 scores do not indicate clearly the generalization level of any of the four subjects after six intervention sessions. It is interesting that, Subject $B I$ 's mother reported that he was using the structure correctly at home at the time of criterion test 1 .

Criterion test 2 TASK 1 was administered after nine intervention sessions and the following results were obtained. Subject Al received a score of 78 percent, using the target structure correctly seven times and incorrectly two times in spontaneous speech. Subject A3 received a score of 22 percent, using the target structure correctly two times and incorrectly seven times. Subject $B 1$ received a score of 100 percent, using the target structure correctly twelve times and incorrectly zero times in spontaneous speech. Subject B2 also received a score of 100 percent, using the target structure correctly five times and incorrectly zero times.

Criterion test 3 TASK 1 was administered following twelve intervention sessions. Subjects Al, B1 and B2 received scores of 100 percent, indicating they all had generalized the target structure to spontaneous speech while subject $A 3$ received a score of 33 percent. To summarize, it appears that two subjects trained with 
Method B generalized the target structure completely (100 percent) to spontaneous speech after nine intervention sessions, while the subjects trained with Method A took longer, with subject Al reaching 100 percent after twelve sessions and subject A3 obtaining a 33 percent proficiency level after twelve sessions.

As indicated earlier, generalization levels of the four subjects following six intervention sessions were unclear due to complications in the testing procedures. However, an examination of test 1 TASK 2 scores provides information as to the subjects' comparative abilities in a relatively spontaneous setting following six intervention sessions. Figure 7 illustrates the four subjects' TASK 2 scores. Both Method B subjects received scores of 100 percent after six sessions; whereas Subjects $A 1$ and $A 3$ received scores of 60 percent and 40 percent, respectively, following six sessions. Therefore, these results and the mother's report of Subject Bl's correct usage at home following six sessions support the test 2 TASK 1 results in suggesting that the answer to question four is that the subjects trained with a traditional syntax program in combination with nontraditional methods (structured play activities) (Method B) generalized the target structure in fewer number of sessions than did the subjects trained with a traditional syntax program (Method A). 


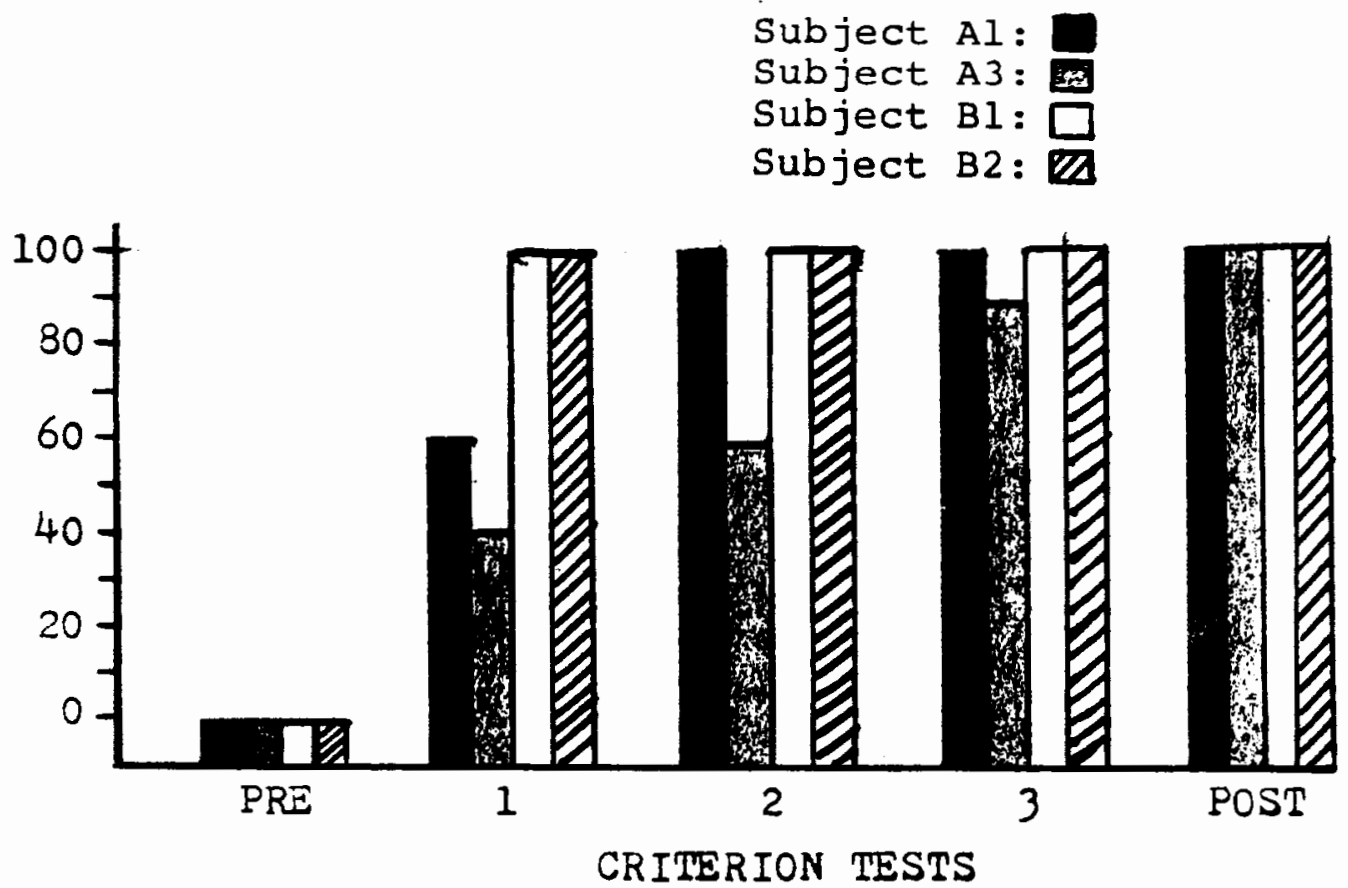

Figure 7. Subject Al, A3, Bl and B2's Scores on TASK 2 for Pre-Criterion Test, Criterion Test 1 , Criterion Test 2, Criterion Test 3 and Post-Criterion Test

Two subjects, one in each method, Subject A2 and Subject B3 did not show generalization of the target structure to spontaneous speech. However, an examination of their TASK 2 scores over time may help determine their relative rates of progress in a relatively spontaneous setting. Figure 8 shows that neither subject clearly progressed faster than the other. However, after twelve sessions, Subject B3 did demonstrate greater generalization in this setting with a score of 100 percent as compared to Subject A2's score of 60 percent.

In conclusion, the results of this study indicate that subjects from both methods made gains in the use of 


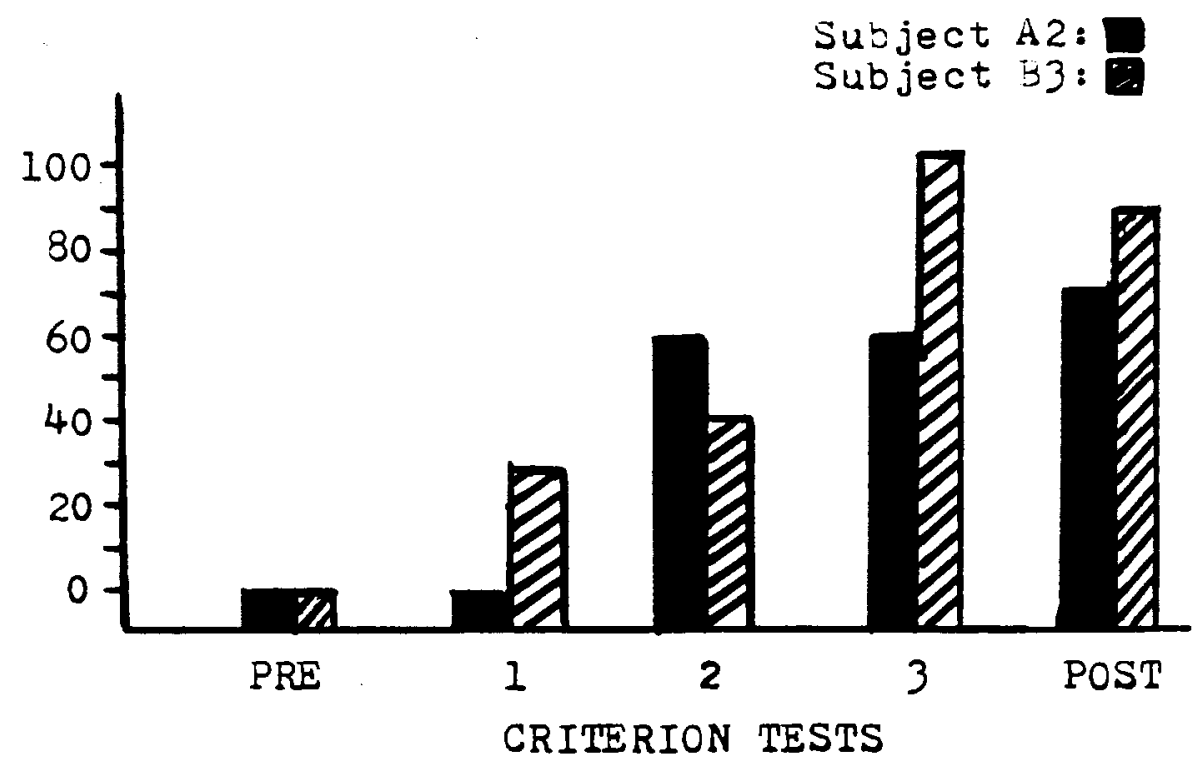

Figure 8. Subject $A 2$ and $B 3$ 's scores on TASK 2 for Pre-Criterion Test, Criterion Test 1, Criterion Test 2, Crieterion Test 3 and Post Criterion Test

the trained syntax structure. However, the group taught with the traditional syntax program in combination with play activities evidenced somewhat faster and greater gains than the group taught with the traditional syntax program.

\section{DISCUSSION}

Success or failure of any language training program can be judged by its ability to improve the client's communicative skills (Garcia and DeHaven, 1984; Hedge, Noll and Pecora, 1979). Syntax structures used correctly in the clinical setting, but not in spontaneous speech, will not improve the client's ability to communicate. Traditional language programs have been successful in 
establishing the trained syntactical structure in the clinical setting, but according to speech-language pathologists in the field, generalization of the target structure to spontaneous speech continues to be a significant problem (Mulac and Tomlinson, 1977; Guess, Keogh and Sailor, 1978; Rees, 1978). Recent literature in the areas of semantics and pragmatics suggests the problem may be due to the targets being trained out of natural context. This study sought to examine and compare generalization results of a program using traditional techniques with one using both traditional and nontraditional techniques (structured play activities).

Before discussing the results of this study, it is necessary to address a very relevant question. Are the post-test samples of spontaneous speech obtained during play with a tester other than this investigator, in a clinic room, representative of the subjects' spontaneous speech in other settings such as the home environment? As no home samples were taken, the answer is at best speculative. The fact that subject $A 3$ responded differently when the investigator was in the testing room than when she was not, indicates that using someone other than the investigator for testing is important in obtaining truly spontaneous results. Likewise, using a setting other than a clinic room where intervention sessions were delivered, may be just as crucial in obtaining spontaneous speech. 
In this study, the clinic room may have been a stimulus for correct use of the target structure. Hart and Risley (1968) found that once their subjects established the target in play, they generalized it to all settings in the school. However, as in this study, no home samples were obtained. Mulac and Tomlinson (1977), who did obtain home samples, found that there was no difference in the use of the target in samples collected in a clinic playroom and those collected by the parent at home. In conclusion, caution must be taken in reviewing the results of this study, as it is not known whether the spontaneous samples gathered during play in the clinic room, were representative of speech in other settings.

In answer to the first two questions posed in this study, results indicate that both methods, a traditional syntax program and a traditional syntax program in combination with structured play activities, were partially successful in obtaining generalization of the target structure to spontaneous speech. How these results compare to past studies will now be examined.

Training with the Monterey Language Program (MLP) produced poorer generalization results than would be expected from Gray and Ryan's (1973) study and better generalization results than would be expected from Mulac and Tomlinson's (1977) negative findings and the concern found in the literature regarding poor generalization 
results of traditional programs. Gray and Ryan (1973) found that after their clients completed a program, i.e., met criterion on the conversation step, completed the home carry over program and received a score of at least 80 percent on the MLP criterion test, generalization was noted in their conversational speech. All three subjects met the above listed criterion and yet, not all of them generalized the structure to spontaneous speech.

Mulac and Tomlinson (1977) found that their subjects trained with the MLP, demonstrated no significant generalization of the trained syntactical structure to spontaneous speech. Yet in this study, one subject totally generalized the target to spontaneous speech and another, Subject A3, showed a pattern of increasingly higher TASK 1 scores, suggesting that had he received a few more sessions, he too may have achieved total generalization. No such growth pattern is seen in subject A2's TASK 1 scores. This study's superior results could be due to the structure chosen for training. It may be easier to generalize the use of pronouns (taught in this study) than the use of the "is-interrogative" structure (Mulac and Tomlinson, 1977), as seemingly, pronouns occur in greater frequency in conversational speech and, thus, would be subject to more practice.

This study's more positive results than reported in the literature on generalization results of traditional 
programs, could have been due to the great care taken in this study to follow the MLP explicitly. It is possible, that some clinicians do not explicitly and completely follow generalization programming when and if it is available, such as with the MLP. Some clinicians may not attempt the generalization step of a program as they may see their role as one in which teaching in the clinic rather than training parents and programming for the home environment is top priority or, they may have had difficulty in obtaining parental cooperation in the past and, thus, might have low expectations concerning parental involvement. On the other hand, clinicians may attempt to involve parents and find they are inconsistent in following the program. It is probable that parents involved in this study were more cooperative than many parents of children in the public schools. The parents in this study showed an active concern for their children's speech and language development by seeking remediation for their children, consenting to transport their children to the clinic three times a week, observing most of the sessions and completing the home carry over program. Parents in the public schools often take a much more passive role. It is the speech-language pathologist who expresses concern regarding their child's speech and it is the school who transports their children. Contact between the speech-language pathologist and parents is usually minimal 
due to time constraints. In summary, parents in this study were highly motivated, active participants in their children's progress. Completion of the home carry over program was but a small part of their total commitment. In contrast, parents in the public schools are often passive observers of their children's progress and, thus, may not be as motivated to become involved in a home carry over program.

Two subjects trained with Method $B$, a traditional syntax program in combination with structured play activities, generalized the target structure to spontaneous speech, while the other subject did not generalize to spontaneous speech, but did use the target structure correctly 90 percent of the time in relatively spontaneous settings. These positive results compare similarly to results reported by Hart and Risley (1968) and Hubbell (1977), neither of which reported data on generalization. However, both concluded from their studies that structured training in combination with the use of natural context was effective in training language delayed children.

Question three asked about the relative effectiveness of the two methods used in this study. Results indicating that Method B, a traditional syntax program in combination with structured play activities, produced slightly better generalization results, are tentative at best, as it demonstrated only a slight advantage over Method A, a 
traditional syntax program. Both failed to produce generalization in one subject. Of the remaining subjects, two subjects trained with Method B obtained 100 percent generalization, while one subject trained with Method A obtained 100 percent and the other 40 percent. It is difficult to discern whether these results are due to differences in the methods used, or perhaps, differences in the subjects composing the two groups. An effort was made to match the subjects. However, it is impossible to control all possible variables.

A multiple baseline design, where one subject is administered both methods and the results of the two are compared, may be a more appropriate means of comparing two different remediation approaches. For example, Handelman (1979) while using such a design, found that training a target in a restricted setting resulted in little generalization, whereas multiple natural settings yielded somewhat greater generalization for three of the four subjects. The other subject evidenced greater generalization regardless of the setting. In this study, it is not possible to tell whether one subject would have performed better, worse or the same after training in either method. However, an effort will be made to investigate the matched pairs and examine variables which may have contributed to positive or negative generalization results.

An examination of Appendix $D$ indicates that Subjects 
$A l$ and $B l$ are very well matched on all listed variables. In addition, neither subject appeared to differ on such subjective unlisted variables as attending behavior, motivation and parental support. Interestingly, they both generalized the target structure to spontaneous speech.

Subjects A2 and B2 are matched on Mean Length of Utterance (MLU), but Appendix $D$ shows that they differ in some variables. Since subject $B 2$ is one year older and yet has nearly the same MLU as Subject A2, it would appear that he has the more severe expressive language deficit. In addition, his receptive vocabulary is three months below age level, while subject A2's is nine months above age level. Subject B2 has had seven terms of previous remediation as compared to Subject $A 2$ 's four terms. Both have previously worked on the target structure for one term. However, during pre-testing, the only task that either scored above 0 percent on was TASK 5 (imitation), in which subject A2 scored 70 percent and subject B2 scored 40 percent. One major difference between the two is that subject A2 had thirty-eight errors on the Photo Articulation Test as compared to subject B2's score of seventeen errors. All of subject B2's errors were above age level substitution errors, while many of subject A2's errors were below age level omission errors, which are generally regarded, as indicative of a more severe articulation disorder. To summarize, subject $B 2$ is older, has 
more terms of previous remediation, seems to have poorer receptive and expressive language skills and better articulation skills. Yet, Subject B2 generalized the target structure to spontaneous speech, while subject A2 did not. Perhaps, Subject B2 was more "ready" to learn the structure due to his age and past remediation experiences. Or perhaps Subject A2's articulation deficit in addition to his expressive language deficit indicates a more global language impairment which negatively effected remediation. However, this is only speculation about an unexplainable event and does not indicate that the MLP should not be used with articulation clients.

Subjects A3 and B3 appear to be well matched on all variables listed in Appendix $D$, with the exception of scores on the photo Articulation Test and the Speech Intelligibility Index. Neither had any previous remediation experiences, both received receptive vocabulary scores between ten and eleven months above age level and both received slightly higher MLU's than the other subjects. Subject B3's articulation errors included below age level substitutions which decreased her intelligibility, whereas subject $A 3^{\prime}$ 's errors all appeared to be developmental and did not affect his intelligibility. Subject A3 generalized the target structure to a proficiency level of 40 percent in spontaneous speech while Subject B3 showed no generalization in spontaneous 
speech. Again, it is interesting to note that it is the subject with the combined articulation and expressive language delay that did not generalize the structure.

An interesting question about which to speculate is why did Subject $A 3$, who did not have an additional articulation deficit, as did the other two subjects who failed to generalize, only partially generalize the target structure? In many ways he resembles subjects $A l$ and $B l$, who both generalized. Although, he does have slightly higher receptive and expressive language abilities. The major way that Subject $A 3$ differs from Subjects $A 1$ and $B 1$ is that this study was his first remediation experience; whereas the other two both had had two terms of previous remediation. One could speculate, therefore, that had he entered the study with more "know how" concerning a clinic setting, he may have also generalized completely. Continuing with this speculation, both methods would, thus, have produced generalization in two subjects each and both would have failed to promote generalization in one subject each. Speculation such as this demonstrates the frailty of Method B's suggested advantage.

Question number four asked whether either method produced faster generalization results. The results indicate that the traditional syntax program in combination with structured play activities (Method B) produced slightly Easter generalization. Again, subject 
variability may have been a factor. Subject $A 3$ may have been slower because of his lack of previous remediation experiences. Subject B2 may have been faster because of his age and previous remediation experiences. However, Subjects $A l$ and $B l$ are very well matched, and yet subject Bl generalized the target structure by the end of the ninth intervention session and possibly even by the sixth session; whereas Subject Al did not generalize until after the twelfth session. Thus, one could speculate that in this case, it was the method which generated the difference in results.

An obvious reason why Method B may have produced quicker results than Method $A$, is that it started generalization programming at the beginning of remediation, rather than at the end. Another reason may be the similarity between Method B's programmed generalization content (play activities) and the subjects' "normal home activities." Handelman (1979) suggests that by making school more like home, generalization would be facilitated. Method A's programmed generalization content consisted of two facets: 1) the last step of each program, the conversation step and 2) the home carry over program. The term "conversation" is misleading, as responses required in this step are very structured, with remarks not containing the target structure, not to exceed 5-10 percent of the conversation. Likewise, the home 
carry over program is structured. The parent simply asks questions about pictures in books to elicit the target structure. The child's responses are marked correct or incorrect. It is suggested that Method B shared more stimuli in common with the home environment than Method A and, thus, produced faster and slightly better generalization results.

It could be contended that Method B produced positive results, not so much because training occurred in a natural situation and, therefore, facilitated generalization, as to the fact, that testing conditions were more similar to training conditions for Method B subjects than for Method A subjects. Method B subjects spent half of each session in play activities in the clinic room. Testing occurred in the same or similar clinic room, with TASK I being a fifteen play period with a tester other than the investigator. No toys used in training were used in testing, however, similarities were difficult to avoid. It could be that the clinic room and a play setting acted as stimuli for correct use of the structure for Method B subjects.

In conclusion, one cannot say that either method was totally adequate or inadequate in producing generalization of the target syntactical structure. Both the traditional syntax program and the traditional syntax program in combination with structured play activities, produced 
clients who generalized the structure and, likewise, a client who failed to generalize the structure to spontaneous speech. The traditional syntax program in combination with play activities seemed to produce slightly better and faster generalization results to spontaneous speech in a clinic room, however, for reasons previously discussed, these comparative results are at best tentative. 
CHAPTER V

SUMMARY AND IMPLICATIONS

SUMMARY

The effectiveness of any language training program is determined by generalization of the clinically trained behaviors to spontaneous speech (Hedge, Noll and Pecora, 1979). Traditional language programs which employ operant procedures to establish the behavior in the clinic and reinforcement from family, teachers and peers in a variety of settings to obtain generalization, have been successful in establishing the use of grammatical rules in the clinic setting, but reportedly have failed to promote generalization (Rees, 1978). Recent literature in the areas of semantics and pragmatics has produced a trend toward teaching language in natural contexts. The purpose of this study was to investigate: 1) whether a group taught with a traditional syntax program would generalize the trained structure to spontaneous speech, 2) whether a group trained with a traditional syntax program in combination with nontraditional methods (natural context) would evidence generalization, 3) whether one of the above methods would evidence greater, lesser or the same generalization and 4) which method would take fewer, the same or 
greater number of sessions.

Six subjects ranging in age from 4 years 7 months to 5 years 10 months were selected. All demonstrated normal hearing, normal receptive language abilities and delayed expressive language abilities. Subjects were matched according to Mean Length of Utterance and omission of a particular grammatical rule. One of each pair was randomly placed in one of the two intervention groups. Method $A$ was the Monterey Language Program and Method $B$ was the Monterey Language Program used during the first half of each session and play activities during the second half. Intervention consisted of three twenty-five minute sessions a week for twelve sessions. A criterion test, devised to measure generalization, was administered before intervention, three times during intervention and one week following intervention.

Results indicated that one subject trained with Method A evidenced generalization of the structure, one failed to demonstrate generalization and the other was beginning to show generalization. These results are not as good as would be expected from Gray and Ryan's (1973) report, but better than would be expected from both Mulac and Tomlinson's (1977) study and reports from the field of poor generalization results of traditional programs. Two subjects trained with Method B evidenced generalization of the structure while one did not. Therefore, it appears 
that Method B was slightly more effective than Method A. However, if Subject A3 had entered the study with previous remediation experience, he may also have achieved generalization and then the methods would have been equally effective. It is interesting to note, that the two subjects who failed to generalize, one trained with Method $A$ and the other with Method B, exhibited articulation disorders as well as expressive language delays. Of the subjects who did generalize, the two Method B subjects took fewer sessions than did the two Method A subjects. As two of these subjects, Al and Bl, were very well matched on several variables, the difference in the rate of generalization may have been due to the methods used. However, results are at very best tentative, as with such a small sample individual subject variables may have influenced the generalization results. A multiple baseline study may help determine whether the difference was due to a teaching method or to subjects. individual characteristics.

\section{IMPL ICATIONS}

\section{Clinical}

It was noted earlier that all three subjects trained with the MLP passed its criterion for termination of their respective programs with equal success. Yet, only one had generalized the structure to spontaneous speech. In other 
words, the criterion results did not correlate with spontaneous speech in two of the three clients. This indicates the need for stricter criterion before a client is terminated from a program. Spontaneous language samples are the obvious solution. An unplanned incident in this study indicated that a subject's performance improved when the investigator was in the testing room. Therefore, in order to obtain a valid representation of a client's spontaneous speech, someone other than the clinician should elicit the sample.

Just as criterion used for completion of a traditional syntax program becomes suspect, so does the use of imitative language tests as indicators of pre-post remediation gains. Five subjects scored 100 percent on post-test TASK 5 (imitation) and one subject scored 90 percent. Yet, only three of those subjects generalized the structure to spontaneous speech. Therefore, imitative language tests may not correlate with spontaneous speech, especially following an imitative language program.

The relatively good results of an explicitly followed traditional syntax program should encourage clinicians to follow through on programmed generalization steps, especially when clients have cooperative and responsive parents. Language programs should not be regarded as failures until they have been followed to the last detail and still do not obtain the desired response. 
This study seemed to indicate that both methods were more successful with clients exhibiting expressive language delays not complicated by articulation disorders. It could be, that clients with combined disorders need more sessions of programmed generalization which occurs in varied multiple settings with several people involved.

The results of this study tentatively imply that play activities used in combination with a traditional syntax program may promote slightly better and faster generalization than traditional syntax programs alone. Even though the generalization difference between the two methods was only slight, clinicians may choose the traditional syntax program in combination with play activities because of certain advantages. The primary advantage of Method B over traditional language programs is that generalization was facilitated without dependency upon outside personnel, such as parents, teachers or peers. In the public school setting, finding and coordinating time for training the designated people can prevent even starting traditional generalization programming. Once people are trained, the consistency with which they follow instructions is out of the clinician's control. In addition, the use of outside personnel often requires oversimplification of the response demanded of the client, such as with the MLP home carry over program. In contrast, the clinician is in total control of planning 
play activities, i.e., having an ability to match the amount of structure used with that needed by the client.

Another advantage to play activities is that they are highly motivating. Traditional language programs require less active participation and are less easily modified according to a particular client's interests. Play activities can be carefully planned around each client's unique interests.

Another advantage to using play activities, is that goals other than correct syntax usage, can be targeted. For example, dolls can be used to model appropriate ways of initiating conversations with strangers while also focusing on correct usage of the pronoun "I." Vocabulary can also be taught at the same time as correct syntax usage, through the use of structured play activities. In summary, the advantages of using play activities are numerous enough to make it a valuable procedure in language training.

\section{Research}

While the results of this study cannot be generalized due to the small sample size, they do warrant further investigation. Very little research has been done on the topic of generalization. There is a great need to find the optimal conditions which promote generalization. Training language in a play setting may be a very efficient means of programming for generalization. However, 
the effectiveness of this approach requires a study which could verify the correlation between speech used in the clinic play setting and speech used in the home setting.

Other questions which arise from this follow. Since play activities promoted generalization in syntax training, would they also be effective in combination with traditional articulation programming? Likewise, would play activities in combination with more traditional techniques of teaching basic concepts, be more effective? For example, would clients learn their "colors" faster if the first half of each session was spent in direct instruction and the second half on play activities designed to elicit the use of the trained colors? Do play activities in combination with traditional techniques work better with less severely delayed clients? Are imitative language tests a valid representation of spontaneous speech following training with an imitative language program? Would the multiple baseline design be useful in research comparing different methods of promoting generalization? Clinical research studies designed to answer the above questions may provide information on how to improve functional communicative abilities. "Functional" is the key word. If clients do not use what they learn in the clinic outside of that clinic to communicate, training has failed to improve functional communicative abilities. 
SELECTED BIBLIOGRAPHY 


\section{SELECTED BIBLIOGRAPHY}

BATES, E. (1976). Language and Context: The Acquisition of Pragmatics. New York: Academic Press.

BLOOM, L. (1970). Language Development: Form and Function in Emerging Grammars. M.I.T. Press.

BOWERMAN, M. (1978). Semantic and syntactic development. In R.L. Schiefelbusch, Ed., Bases of Language Intervention. Baltimore: University Park Press.

BRICKER, W.A., and BRICKER, D.A. (1970). A program of language training for the severely language handicapped child. J. Appl. Behav. Anal., 37, 101110 .

BRUNER, J.S. (1975). The ontogenesis of speech acts. J. Child Lang., 2, 1-19.

CHOMSKY, N. (1957). Syntactic Structures. The Netherlands: Mouton \& Co.

CHOMSKY, N. (1959). Review of Skinner (1957). Language, $35,26-58$.

DALE, P.S. (1976). Language Development: Structure and Function. New York: Holt Rinehart and Winston.

DUNN, L.M. (1965). Peabody Picture Vocabulary Test. Circle Pines, Minn.: American Guidance Service.

EMERICK, L., and HATTEN, J. (1974). Diagnosis and Evaluation in Speech Pathology. Englewood Cliffs, New Jersey: Prentice-Hall.

GARCIA, E. (1974). The training and generalization of a conversational speech form in nonverbal retardates. J.Appl. Behav. Anal., 7, 137-149.

GARCIA E., and DeHAVEN, E. (1974). Use of operant techniques in the establishment and generalization of language: A review and analysis. American Journal of Mental Deficiency, 79, 169-178.

GRAY, B., and RYAN, B. (1973). A Language Program for the Nonlanguage Child. Champaign: Research Press. 
GUESS, D. , KEOGH, W., and SAILOR, W. (1978). Generalization of speech and language behavior. In R.L. Schiefelbusch, Ed., Bases of Language Intervention. Baltimore: University Rark Press.

GUESS, D., SAILOR, W., and BAER, D. (1974). To teach language to retarded children. In R.L. Schiefelbusch, Ed., Language Perspectives: Acquisition, Retardation and Intervention. Baltimore: University Park Press.

GUESS, D., SAILOR, W., RUTHERFORD, G., and BAER, D. (1968). An experimental analysis of linguistic development: the productive use of the plural morpheme. J. Appl. Behav. Anal., 1, 225-235.

HANDLEMAN, J. (1979). Generalization by autistic-type children of verbal responses across settings. J. Appl. Behav. Anal., 12, 273-282.

HARRIS, S.L. (1975). Teaching language to nonverbal children with emphasis on problems of generalization. Psychological Bulletin, 82, 565-580.

HART, B.M. and RISLEY, T.R. (1968). Establishing use of descriptive adjectives in the spontaneous speech of disadvantaged preschool children. J. Appl. Behav. Anal., 1, 109-120.

HARTUNG, J.R. (1970). A review of procedures to increase verbal imitation skills and functional speech in autistic children. J. Speech Hearing Dis., 35, 203-217.

HEDGE, M.N. and GIERUT, J. (1979). The operant training and generalization of pronouns and a verb form in a language delayed child. J. Commun. Dis., 12, 23-34.

HEDGE, M.N., NOLL, M.J., and PECORA, R. (1979). A study of some factors affecting generalization language training. J. Speech Hearing Dis., 44, 30l-320.

HOLLAND, A.L. (1975). Language therapy for children: Some thoughts on context and content. J. Speech Hearing Dis., 40, 514-523.

HUBBELL, R.D. (1977). On facilitating spontaneous talking in young children. J. Speech Hearing Dis., 42, $216-231$. 
KENT, L. (1972). A language acquisition program for the retarded. In J.E. McLean, P.E. Yoder and R.L. Schiefelbusch, Eds., Language Intervention with Retarded. Baltimore: University Park Press.

LEE, L.L. (1974a). Developmental Sentence Analysis.

Evanston: Northwestern University Press.

LEE, L.L. (1974b). Linguistic approaches to developmental language disorders. Folia Phoniat., 26, 33-67.

LEONARD, L.B. (1975). The role of nonlinguistic stimuli and semantic relations in children's acquisition of grammatical utterances. J. Exp. Child Psychol., 19, 346-357.

LUCAS, E.V. (1980). Semantic and Pragmatic Language Disorders Assessment and Remediation. Rockville: Aspen Systems Corporation.

LUTZKER, J.K., and SHERMAN, J.A. (1974). Producing generative sentence usage by imitation and reinforcement procedures. J. Appl. Behav. Anal., 7, 447-460.

MacDONALD J.D. (1978). Environmental Language Inventory. Columbus: Bell \& Howell Co.

MAHONEY, G., and SEELY, A.B. (1976). The role of social agent in language acquisition: Implication for intervention. In N.R. Ellis, Ed., International Review of Research in Mental Retardation. New York: Academic Press.

MARTIN, J.A. (1975). Generalizing the use of descriptive adjectives through modeling. J. Appl. Behav. Anal., 8, 203-209.

MCCORMICK, L.P., and ELDER, P.S. (1978). Instructional strategies for severely language deficient children. Education and Training of the Mentally Retarded, 13, 29-35.

MCLEAN, J.E., and SNYDER-MCLEAN, L.K. (1978). A Transactional Approach to Early Language Training. Columbus: Bell \& Howell Co.

MCNEIL, D. (1966). Developmental psycholinguistics. In Smith and Miller, Eds., The Genesis of Language. Cambridge, M.I.T. Press. 
MILLER, L. (1981). The remediation of auditory language learning disorders. In R.J. Roeser and M.P. Downs, Eds., Auditory Disorders in School Children. New York: Theme-Stratton.

MULAC, A., and TOMLINSON, C.N. (1977). Generalization of an operant remediation program for syntax with language delayed children. J. Commun. Dis., 10, 231-243.

MUMA, J.R. (1978). Language Handbook-Concepts, Assessment, Intervention. Englewood Cliffs, New Jersey: Prentice Hall.

NELSON, K. (1974). Concept, word and sentence: Interrelations in acquisition and development. Psychological Review, 81, 267-85.

PENDERGAST, K., DICKEY, S., SELMAR, J., and SODER, A. (1965). Photo Articulation Test. Chicago, Ill.: The King Company, Pub.

REES, N.S. (1978). Pragmatics of language. In R.L. Schiefelbusch, Ed., Bases of Language Intervention. Baltimore: University Park Press.

RISLEY, T., and WOLF, M. (1968). Establishing functional speech in ecolalic children. In H.N. Sloane, Jr., Ed. Operant Procedures in Remedial Speech and Language Training. Boston: Houghton Mifflin Co.

RUDER, K.F. (1978). Planning and programming for language intervention. In R.L. Schiefelbusch, Ed., Bases of Language Intervention. Baltimore: University Park Press.

RUDER, K.F., and SMITH, M.D. (1974). Issues in language training. In R.L. Schiefelbusch, Ed., Language Perspectives-Acquisition, Retardation, and Intervention. Baltimore: University Park Press.

SAILOR, W., GUESS, D., and BAER, D.M. (1973). Functional language for verbally deficient children: An experimental program. Mental Retardation, 11, 27-35.

SAILOR, W., and TAMAN, T. (1972). Stimulus factors in the training of prepositional usage in three autistic children. J. Appl. Behav. Anal., 5, 183-190.

SCHIEFELBUSCH, R.L. (1978). Introduction. In R.L. Schiefelbusch, Ed., Bases of Language Intervention. Baltimore: University Park Press. 
SCHUMAKER, J., and SHERMAN, J.A. (1970). Training generative usage by imitation and reinforcement procedures. J.Appl. Behav. Ana 1., 3, 273-287.

SKINNER, B.F. (1957). Verbal Behavior. New York: Appleton-Century-Crofts, Inc.

SLOANE, H.N., JOHNSTON, M.K., and HARRIS, F.K. (1968).

Remedial procedures for teaching verbal behavior to speech deficient or defective children. In H.N. Sloane, Ed., Operant Procedures in Remedial Speech and Language Training. Boston: Houghton Mifflin Co.

SLOBIN, D.I. (1968). Imitation and grammatical development in children. In N.S. Endler, L.S. Boulter and H. Osser, Eds., Contemporary Issues in Developmental Psychology. New York: Holt, Rinehart and Winston.

VAN RIPER, C. (1972). Speech Correction. Englewood Cliffs: Prentice-Hall, Inc.

WHEELER, A.J. and SULZER, S. (1970). Operant training and generalization of a verbal response form in nonverbal retardates. J. Appl. Behav. Anal., 3, 139-147. 


\section{APPENDICES}


APPENDIX A

PERMISSION FORM A

I agree to let my child_have her/his hearing and language screened by Jeanne Goodling, a Portland State University Graduate student in Speech Pathology and Audiology. Mary Gordon, Director of Speech and Hearing Science Program at Portland State Univerity, will supervise the screening.

The purpose of the screening is to obtain subjects for a study entitled: "Effects of Two Management. Techniques on the Generalization of a Syntax Structure." Only a few of the children screened will actually be used as subjects. If my child is screened and seems to be appropriate for this study, another permission form will be sent home to me for approval or disapproval of her/his participation in the study. Permission Form A allows Jeanne Goodling only to screen my child's hearing and language.

There are no risks or dangers inherent in the screening. My child will 1isten to tones through earphones for the hearing screening and will point at pictures and talk while playing with toys for the language screening.

Al1 information will be kept confidential and the identity of all subjects will remain anonymous. Subjects are free to withdraw from the study at any time.

Signature of Parent/Guardian

Date
Birthdate of child $\overline{\text { Mo. }}-\overline{\text { Day }} \frac{}{\mathrm{Yr}}$.


APPENDIX B

\section{PERMISSION FORM BI}

I agree to let my child participate as a subject in the study entitled "The Effects of Two Management Techniques on the Generalization of a Syntax structure." This study is carried out by Jeanne Goodling under the supervision of Mary Gordon, thesis director, Speech and Hearing Science Program, Portland State University.

The purpose of this study is to compare the relative effectiveness of two techniques for teaching syntax structures. There will be two groups of children involved in this study. One group will be taught using Method A (structured approach using pictures and imitation of the investigator's sentences) and the other group will be taught using Method $B$ (both a structured approach using pictures and imitation and an unstructured approach using play and modeling of correct sentences). (hildren will be randomly placed in Method A or Method B. Your child was randomly placed in Method B. He/she will receive training on a syntax form in three twenty-five minute sessions a week until the program is completed (minimum of 4 weeks and maximum of 6 weeks).

There are no risks or dangers inherent in the procedures of this study. All information will be kept confidential and the identity of all subjects will remain anonymous. Subjects are free to withdraw from the study at any time. 


\section{APPENDIX C}

\section{PERMISSION FORM B2}

I agree to let my child participate as a subject in the study entitled "The Effects of Two Management Techniques on the Generalization of a Syntax structure." This study is carried out by Jeanne Goodling under the supervision of Mary Gordon, thesis director, Speech and Hearing Science Program, Portland state University.

The purpose of this study is to compare the relative effectiveness of two techniques for teaching syntax structures. There will be two groups of children involved in this study. One group will be taught using Method A (structured approach using pictures and imitation of the investigator's sentences) and the other group will be taught using Method B (both a structured approach using pictures and imitation and an unstructured approach using play and modeling of correct sentences). Children will be randomly placed in Method A or Method B. Your child was randomly placed in Method A. He/she will receive training on a syntax form in three twenty-five minute sessions a week until the program is completed (minimum of 4 weeks and maximum of 6 weeks).

I agree to be trained by the investigator to do "homework" (asking your child specific questions at home) with my child for 8 days, 5-10 minutes per day, during the 1ast 2 weeks of the study.

There are no risks or dangers inherent in the procedures of this study. A11 information will be kept confidential and the identity of all subjects will remain anonymous. Subjects are free to withdraw from the study at any time.

Signature of Parent/Guardian

Date 
APPENDIX 0

DESCRIPTION OF SUBJECTS

VARIABLES

SUBJECTS

Pair 1 Pair 2 Pair 3 Mean

AGE

Method A

$4 y r 11 \mathrm{mo}$

$4 y r 10 m o$

$4 y r 9 m o$

$4 y r \quad 10 m o$

Method B

5yr 2mo

5yr 10mo

$4 y r 7 m o$

4yr $11 \mathrm{mo}$

SEX

Method A

Pair 1

Pair 2

Pair 3

Method B

PREVIOUS

REMEDIATION

(terms in

clinic)

Method A

M

M

M

M

M

F

Method $B$

Pair 1

Pair 2

Pair 3

Mean

2

4

o

2

2

7

3

PREVIOUS

REMEOIATION

ON STRUCTURE (terms in clinis)

Method A

Pair 1

Pair 2

Pair 3

Mean

0

1

0

.33

Method B

0

1

.33

PEABODY

PICTURE

VOCABULARY

TEST

(months below

or above age

Tevel)

Method A

Pair 1

Pair 2

Pair 3

Mean

Method B

$-2 m o$

+9 mo

$+10 \mathrm{mo}$

$+5.6 \mathrm{mo}$

-3 mo

$-3 m o$

$+11 \mathrm{mo}$

$+1.6 \mathrm{mo}$

MEAN

LENGTH

UTTERANCE

Method A

Pair 1

Pair 2

Pair 3

Mean

Method B

4.54

4.28

5.14

4.65

4.56

4.34

5.18

4.69 
Description of subjects

Page 2

VARIABLES

PHOTO

ARITICULATION

TEST

(total number

of errors)

SPEECH

INTELL IGIBILITY

INDEX

PRE-CRITERION

TASK 5 SCORE

(Percentage

correct out

of ten)

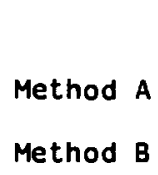

Method B

Method A
Method B

Method $\mathrm{B}$
SUBJECTS

$\begin{array}{cc}\text { Pair 1 } & \text { Pair 2 } \\ 11 & 38 \\ 17 & 17\end{array}$

$\begin{array}{rr}\text { Pair } 1 & \text { Pair } 2 \\ 98 & 86 \\ 96 & 96\end{array}$

Pair 1

Pair 2

Pair 3

Mean

0

70

0

23.3

0

40

30

23.3 


\section{APPENDIX E}

\section{MLP LANGUAGE CURRICULUM}

\section{A Core}

1 Identification of nouns

2 Naming nouns

3 in/on

4 is

5 Is verbing

6 Is in terrogative

7 What is

$8 \mathrm{He} / \mathrm{sh} \theta / \mathrm{it}$

$91 \mathrm{am}$

10 Singular noun present tense

11 Plural nouns present tense

12 Cumulative plural/singular present tense

13 The

B Secondary

14 Plural nouns are

15 Are interrogative

16 What are

$17 \mathrm{You} / \mathrm{they} / \mathrm{w}$

18 Cumulative pronouns

19 Cumulative is/are/am

20 Cumulative is/are/am

in terrogative

21 Cumulative what is/are/am
22 Cumulative noun/pronoun/ verb/verbing

23 Singular and plural past tense ( $t$ and $d$ )

C Optional

24 Was/were

25 Was/were interrogative

26 What was/were

27 Does/do

28 Did

$29 \mathrm{Do} /$ does/did interrogative

30 What is/are doing

$3 i$ What do/does/did

32 Negatives not

33 Conjunction and

34 Intinitive to

35 Future tense to

36 Future tense will

37 Perfect tense has/have

38 Adjectives

39 Possessives

40 This/that/a

41 Articulation 


\begin{abstract}
These are sample questions and resoonses for the criterion tests. They have been serected trom the question series in each program. See the question series in each program for the specific question forms and responses desired. Score only the underlined terms. Substitution of grammatically appropriate words and/or intelligibie misarticulations are permitted. Use pictures or objects. Present five questions for most programs.

Score $=\frac{\text { number correct }}{5} \times 100$ or percentage correct.

5 In programs $8,17,23,25,28,32-36,38.39$ and the cumulative programs $(18,19,20,21$, and 22$)$ present 15 questions and score number correct $\times 100$ or percentage correct.

15 Administer criterion tests before the program and at ter the program has been completed. Use Criterion Test Score Record form.
\end{abstract}

\begin{tabular}{|c|c|c|c|}
\hline $\begin{array}{l}\text { Program } \\
\text { Number }\end{array}$ & Name & Question & Response \\
\hline 1 & $\begin{array}{l}\text { Identification } \\
\text { of nouns }\end{array}$ & Touch the ball. & Child touches ball. \\
\hline 2 & Naming nouns & What is this? & Noun \\
\hline 3 & In/on & Where is the ball? & in the house \\
\hline 4 & is & $\begin{array}{l}\text { Is the ball round or } \\
\text { square? } \\
\text { Where is the tree? }\end{array}$ & $\begin{array}{l}\text { The ball is round. } \\
\text { The tree is in the yard. }\end{array}$ \\
\hline \multirow[t]{4}{*}{5} & Is verbing & $\begin{array}{l}\text { Is the boy walking } \\
\text { or running? }\end{array}$ & The boy is walking \\
\hline & & or & \\
\hline & & $\begin{array}{l}\text { What is the girl holding? } \\
\text { or }\end{array}$ & The girl is holding a pen. \\
\hline & & $\begin{array}{l}\text { Where is the dog } \\
\text { sleeping? }\end{array}$ & $\begin{array}{l}\text { The dog is sleeping on } \\
\text { the floor. }\end{array}$ \\
\hline 6 & Is interrogative & $\begin{array}{c}\text { Guess if the ball is } \\
\text { round or square? } \\
\text { or }\end{array}$ & Is the ball round? \\
\hline
\end{tabular}




\section{MLP OELIVERY VARIABLES}

1) Stimulus. The stimulus precedes the model and the model precedes the response. Both visual (pictures) and auditory (verbal utterances) stimuli are presented. The clinician holds up a picture and describes it with a sentence which follows a pattern written in the stimulus column of the program being administered. See Appendix $H$ for examples. The child does not repeat the stimulus. It merely represents the total final target of what the child will eventualiy be able to say spontaneousiy at the end of the program.

2) Model. The model is the part of the stimulus that the child is expected to produce at any given step of the program. There are five types of models, i.e.. Immediate Complete (IC), Delayed Complete (DC), Immediate Truncated (IT), Delayed Truncated (DT) and No ModeT (N). In the complete models, the teacher models the entire response for the child and the child imitates it. In truncated models, the teacher models onty part of the response and the child is expected to fill in the other words and produce the entire response. In immediate models, the child responds immediately after the teacher presents the model. In delayed models, the child must "hold" the model briefly before he responds. In the last few steps of the program no model is given. Instead, questions are asked about pictures to encourage spontaneous use of the structure. The last step of the programs involves structured conversation with the child. See Appendix $H$ for examples of the different types of models.

3) Response. The response refers to the target behavior. Responses are programmed, starting with easier, shorter responses and gradualiy increase in length and complexity. Appendix $H$ illustrates this progression.

4) Reinforcer. The consequence which follows the response is the reinforcer. The child is reinforced with tokens which can later be traded in for toys. Another reinforcer used, is the utterance "Good." This is spoken as the token is delivered.

5) Reinforcement Schedule. The reinforcement schedule varies throughout a program. When a new skill is being taught there is 100 percent token reinforcement. As the child Tearns the skill, the token reinforcement is faded to 50 percent, then to 10 percent and finaliy to no token reinforcement. For examples, see the column labeled "Sch" in Appendix H. Social reinforcement, "Good," is delivered on a 100 percent schedule throughout all of the programs.

6) Criterion. Criterion refers to the standard of performance the child must exhibit before moving to the next step of the program. If a child does not meet criterion on a particular step, the program provides branching procedures. 
APPENOIX H

ONE OF THE TWO MLP PROGRAMS USED

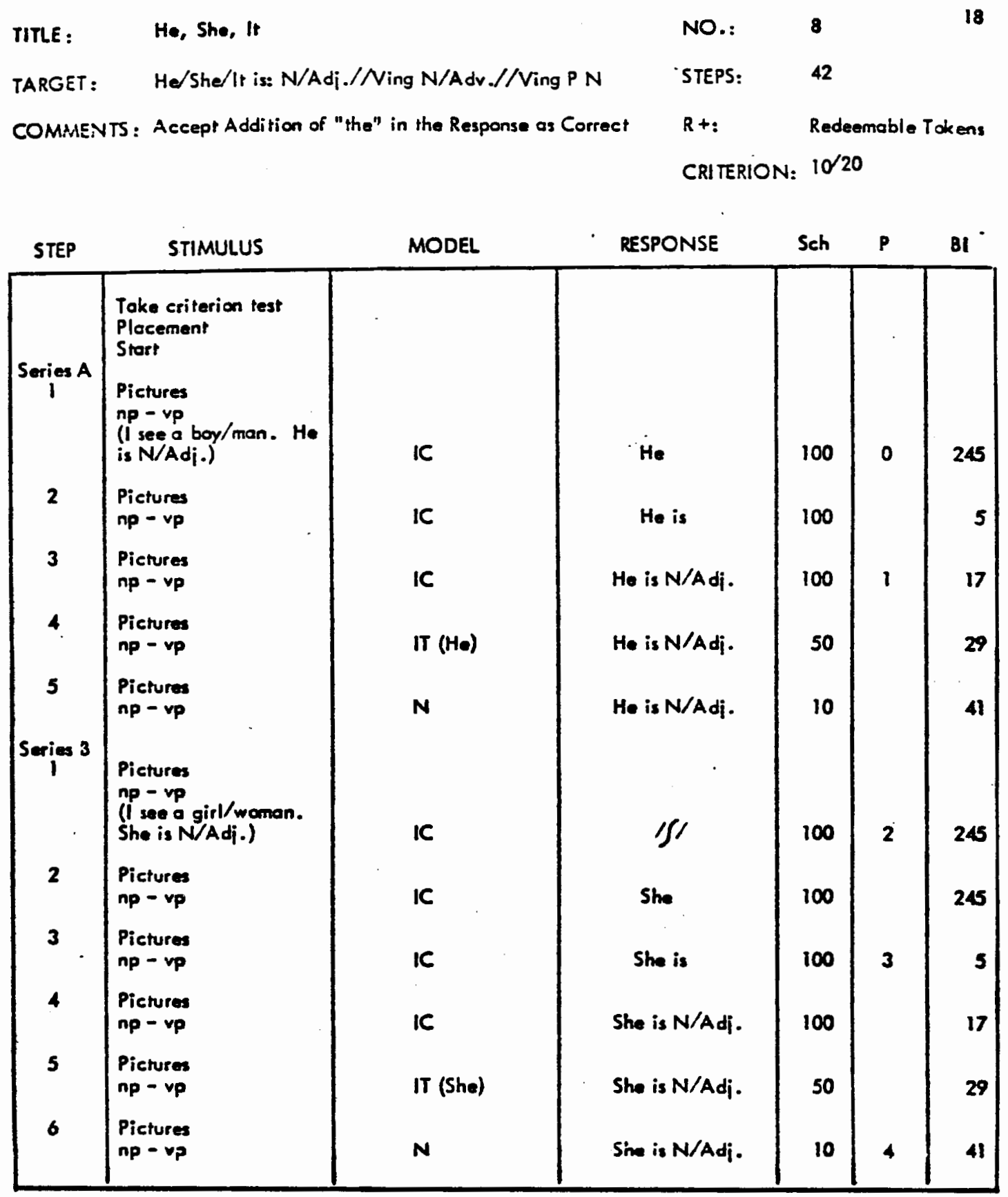


One of the Two MLP Programs Used

Page 2

TITLE: He, She, It

CONTINUATION

$2 / 5$

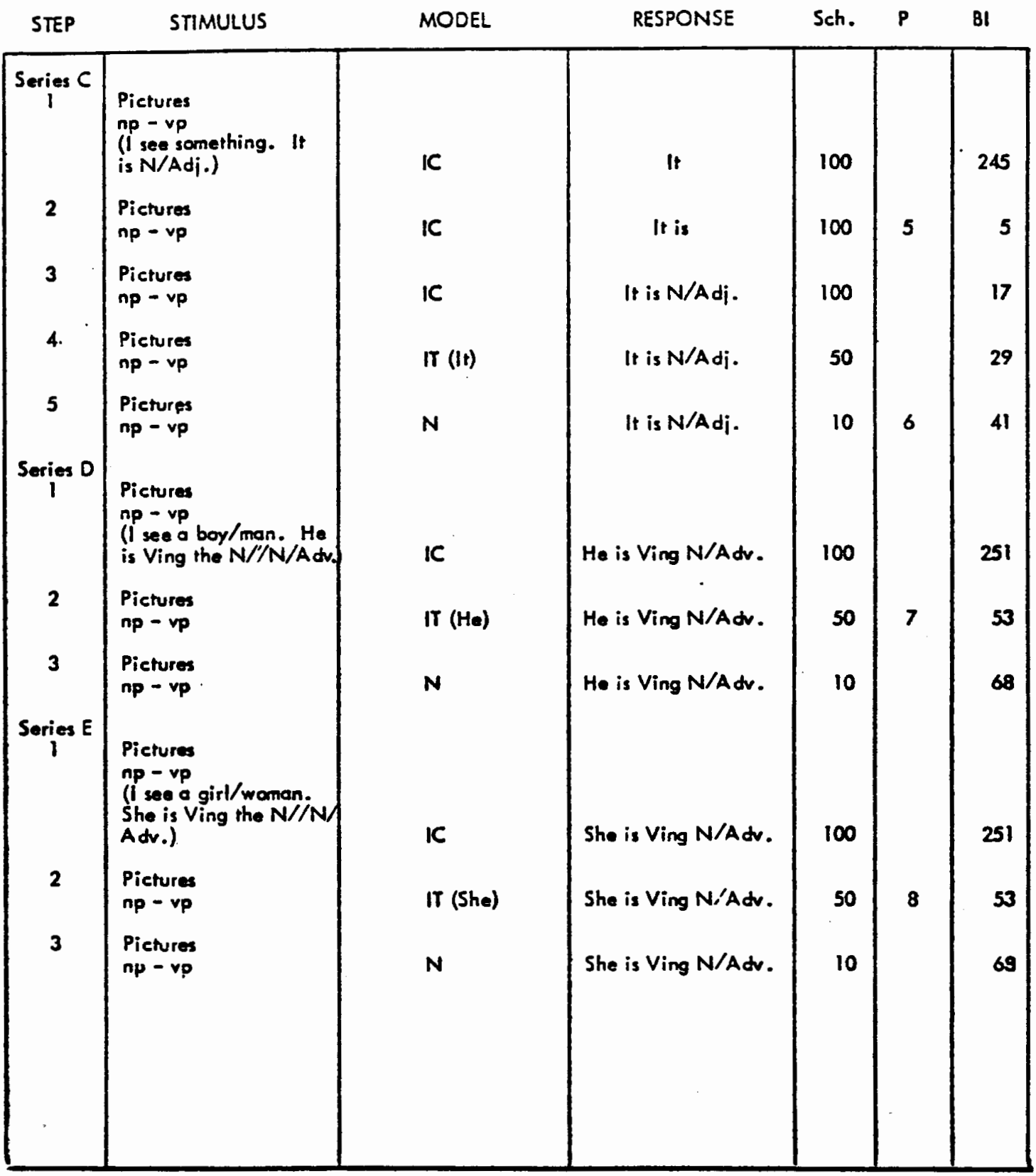


One of the Two MLP Programs Used

Page 3

NITE: He, She, It

CONTINUATION

$3 / 5$

\begin{tabular}{|c|c|c|c|c|c|c|}
\hline STEP & STIMULUS & MODEL & RESPONSE & Sch. & $P$ & 81 \\
\hline Series $F$ & $\begin{array}{l}\text { Pictures } \\
\text { np - vp } \\
\text { (I see something. It } \\
\text { is Ving the } N / / N \text { / } \\
\text { Adv.) }\end{array}$ & IC & It is Ving N/Adv: & 100 & 9 & 251 \\
\hline 2 & $\begin{array}{l}\text { Pictures } \\
n p \text { - vp }\end{array}$ & IT $(1 t)$ & It is Ving $N / A d v$. & 50 & & 53 \\
\hline 3 & $\begin{array}{l}\text { Pictures } \\
n p-v p\end{array}$ & $\mathbf{N}$ & It is Ving N/Adv. & 10 & & 68 \\
\hline$\underset{1}{\text { Series } G}$ & $\begin{array}{l}\text { Pictures } \\
\text { np - vp } \\
\text { ( } 1 \text { see o boy/man. He } \\
\text { is Ving } P \text { the } N)\end{array}$ & IC & $H e$ is Ving $P N$ & 100 & 10 & 252 \\
\hline 2 & $\begin{array}{l}\text { Pictures } \\
n p \text { - vp }\end{array}$ & IT (He) & $\mathrm{He}$ is Ving $P N$ & 50 & & 80 \\
\hline 3 & $\begin{array}{l}\text { Picfures } \\
n p-v p\end{array}$ & $\mathbf{N}$ & $H_{e}$ is Ving PN & 10 & & 101 \\
\hline Series $\mathrm{H}$ & $\begin{array}{l}\text { Pictures } \\
\text { np - vp } \\
\text { (I see a girt/wamen. } \\
\text { She is Ving } P \text { the } N \text { ) }\end{array}$ & IC & She is Ving $P N$ & 100 & 11 & 252 \\
\hline 2 & $\begin{array}{l}\text { Pictures } \\
n p \text { - vp }\end{array}$ & IT (Sha) & She is Ving $P N$ & 50 & & 80 \\
\hline 3 & $\begin{array}{l}\text { Pictures } \\
\text { np - vp }\end{array}$ & $\mathbf{N}$ & She is Ving $P N$ & 10 & & 101 \\
\hline Series 1 & $\begin{array}{l}\text { Pictures } \\
\text { np - vp } \\
\text { (I soe something. It } \\
\text { is Ving P the N) }\end{array}$ & IC & It is Ving P N & 100 & 12 & 252 \\
\hline 2 & $\begin{array}{l}\text { Pictures } \\
n p \text { - vp }\end{array}$ & IT (It) & It is Ving PN & 50 & & 80 \\
\hline 3 & $\begin{array}{l}\text { Pictures } \\
n p-v p\end{array}$ & $\mathbf{N}$ & It is Ving PN & 10 & & (c) \\
\hline
\end{tabular}


One of the Two MLP Programs Used

Page 4

TIRE: He, She, it

CONTINUATION

$4 / 5$

\begin{tabular}{|c|c|c|c|c|c|c|}
\hline STEP & STIMULUS & MODEL & RESPONSE & Sch. & $\mathbf{P}$ & 81 \\
\hline aries J & $\begin{array}{l}\text { Pictures } \\
\text { Combinations } \\
\text { np - vp } \\
\text { (He/sha/it/is: N/Adi/ } \\
\text { Ving the N/Adv/Ning } \\
P \text { the N) }\end{array}$ & IC & $\begin{array}{l}\text { He/she/it/is: N/Adi. } \\
/ / \text { Ving N/AdV/Ving } \\
P N\end{array}$ & 100 & 13 & 247 \\
\hline 2 & $\begin{array}{l}\text { Pictures } \\
\text { Combinations } \\
\text { np - vp }\end{array}$ & $\stackrel{\text { IT }}{(\mathrm{He} / \mathrm{she} / \mathrm{il})}$ & $\begin{array}{l}\text { He/she/it/is: N/Adi. } \\
\text { /Ning N/Adv/Ning } \\
P N\end{array}$ & 50 & & 29 \\
\hline 3 & $\begin{array}{l}\text { Pichures } \\
\text { Combinations } \\
n p-v p\end{array}$ & $\mathbf{N}$ & $\begin{array}{l}\text { He/she/it/iss N/Adi. } \\
\text { /Ning N/Ado/Ning } \\
\text { PN }\end{array}$ & 10 & 14 & 41 \\
\hline 1 & 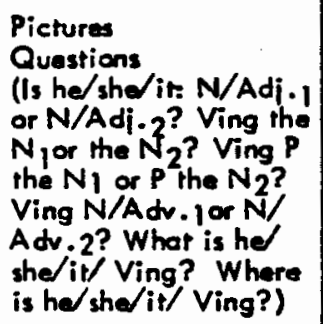 & IC & $\begin{array}{l}\text { He/she/it/ is: N/Adi. } \\
\text { I/Ving N/Adv..// } \\
\text { Ving PN }\end{array}$ & 100 & . & 245 \\
\hline 2 & $\begin{array}{l}\text { Pichures } \\
\text { Questions }\end{array}$ & ${ }_{(H e / s h a / i r)}$ & $\begin{array}{l}\text { He/she/it/ is: N/Adj. } \\
/ \text { Ning } N / A d v . . / \\
\text { Ving P } N\end{array}$ & 50 & & 28 \\
\hline 3 & $\begin{array}{l}\text { Pichures } \\
\text { Questions }\end{array}$ & $\mathbf{N}$ & $\begin{array}{l}\text { He/she/ik/ is: N/Adi. } \\
/ / \text { Ving N'Adv. } / / \\
\text { Ving P N }\end{array}$ & 10 & 15 & 41 \\
\hline 1 & Story & $\mathbf{N}$ & $\begin{array}{l}\text { He'she/ir' is: N/Adi. } \\
/ / \text { Ving N/Adv.// } \\
\text { Ving P N }\end{array}$ & 10 & & 245 \\
\hline
\end{tabular}


104

One of the Two MLP Programs Used

Page 5

2

TITE: He/She/It :

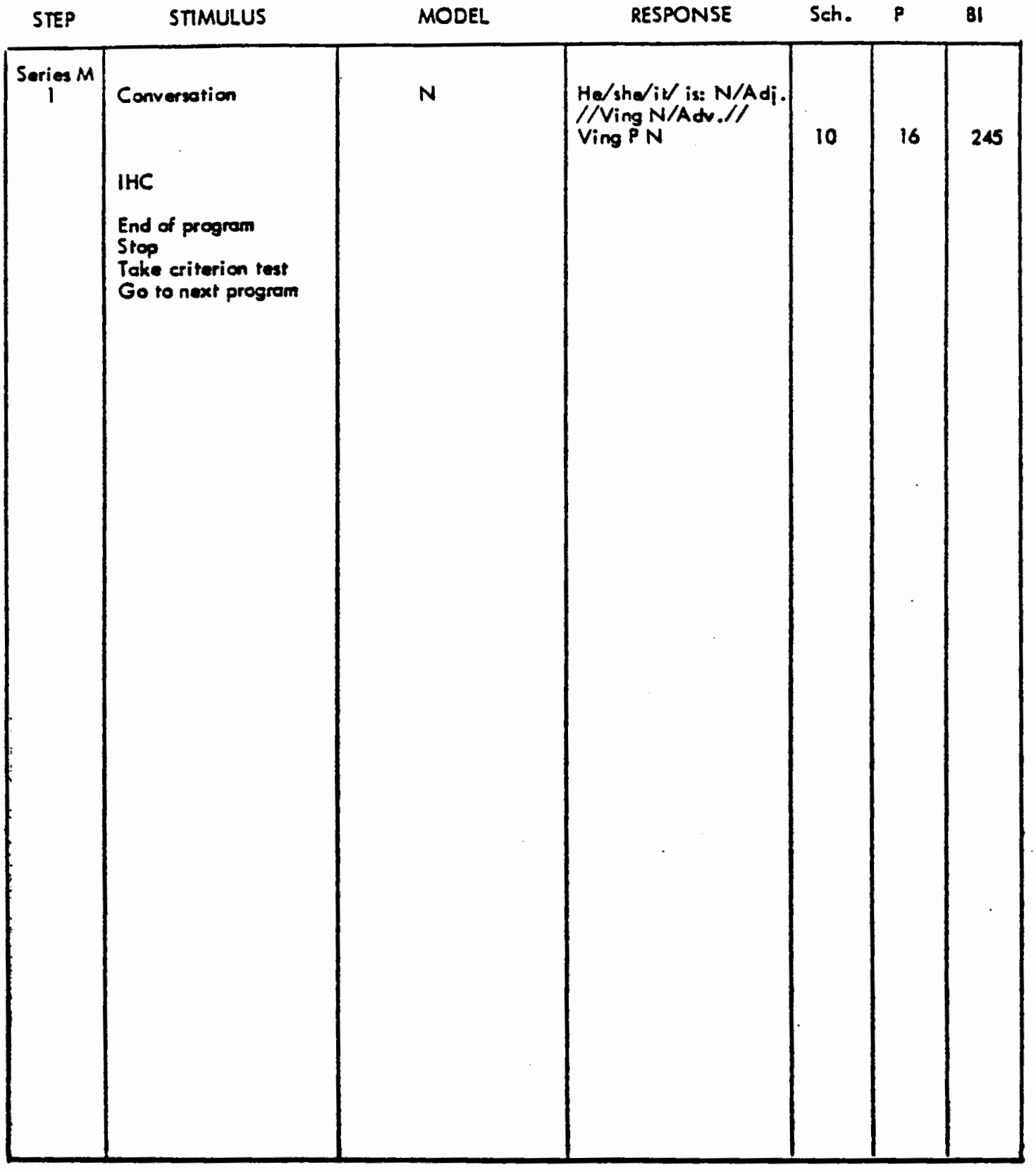




\section{APPENDIX I \\ PLAY INTERACTION PATTERNS}

1) Iangential Play. The investigator and subject played with similar, but separate toys. For example, both colored in their own coloring books. This method is suggested by Van Riper (1972).

2) Cooperative Play. The investigator played with the same toys as the subject. For example, both played with the same dollhouse. This method is suggested by Van Riper (1972).

3) Role playing. Both the investigator and the subject pretended to be different people. For example, the subject pretended to be a mother, while the investigator pretended to be a child in a "tea party" situation. McLean and Snyder-McLean (1978) suggest this technique.

4) Games. Games were developed to elicit specific target structures. See Appendix $K$ for examples. Muma (1978) has used games in language training.

5) Modeling. The investigator provided well-formed sentences to describe both her own and the subject's activities. An effort was made to model the target sentence structure as often as possible. Lucas (1980), McLean and Snyder-McLean (1978), Hubbel1 (1977) and Mahoney and Seely (1976) advocate the use of modeling.

6) Expansion. This term refers to the investigator's response contingent upon a subject's gramatically incomplete or incorrect utterance. For example, if a subject said, "Her running," the investigator corrected and expanded this with "She is running." Lucas (1980) and Muma (1979) suggest this technique in language training.

7) Elicited Imitation. The investigator occasionally asked the subject to imitate a sentence which described an ongoing activity. For example, if a subject, while playing with a dollhouse, made the mother doll cook supper, then the investigator said "Say, she is cooking." 


\section{APPENDIX $J$}

\section{CRITERION TEST}

Subject :

Date:

Tester:

Test:

TASK 1 (spontaneous utterances)

Time: $\quad 15$ minutes

Tester's role: parallel and cooperative play; parallel talking; occasional questioning, such as: "What is happening?", "What should they do?", etc.

St imuli:

toys (

)

Scoring: the percentage of utterances in which the target is used correctly is computed.

\section{IARGET UTTERANCES}

SCORE : \% 
Criterion Test

Page 2

TASK 2 (relatively spontaneous)

Time: amount of time it takes to elicit 10 target structures

St imu $1 \mathrm{i}$ :

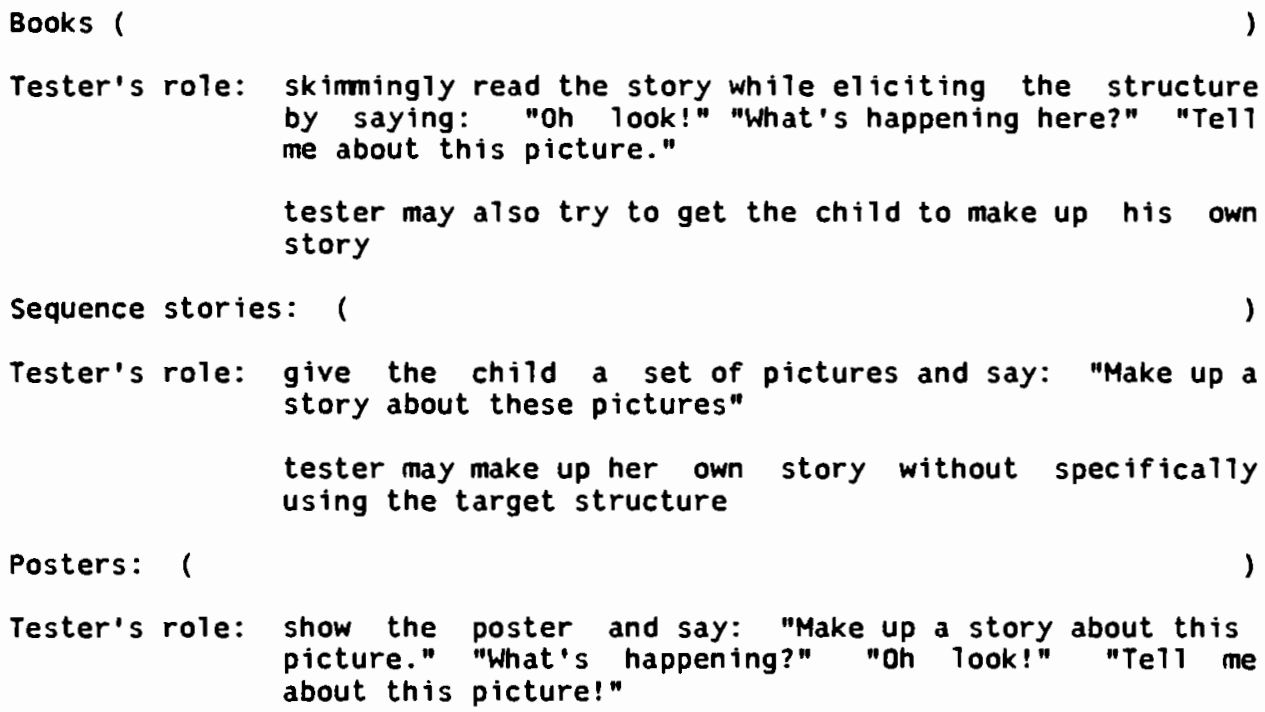

Posters:

Tester's role: show the poster and say: "Make up a story about this picture." "What's happening?" "Oh look!" "Tel1 me about this picture!"

\section{IARGET UTTERANCES}

1. 6.

2 . 7.

3. 8.

4. 9.

5. 10. 
Criterion Test

Page 3

TASK $3(\operatorname{mode} 1)$

Time:

amount of time it takes to show 12 pictures

stimu 1 i :

12 pictures, specifically chosen to elicit the target structure

Tester's role: modeling 2 pictures while using the target structure correctly, for ex: "Listen: She is sliding down the hill (while holding up the appropriate picture)." "Listen again: "She is running home (while showing the appropriate picture)." "Now its your turn. Tell me about these pictures (hold up 10 pictures individual1y)."

\section{IARGET UTTERANCES:}

1.

2.

3.

4.

5.

6.

7.

8.

9.

10.

SCORE : $\%$ 
Criterion Test

Page 4

TASK 4 (questions)

Time: amount of time it takes to show 10 pictures

Stimuli: $\quad 10$ pictures, specifically chosen to elicit the target structure

Tester's role: holding up a picture and asking the question written on the back, such as: "What is she doing?" or "Where are they going?"

\section{TARGET UTTERANCES}

1.

2.

3.

4.

5.

6.

7.

8.

9.

10.

SCORE : $\%$ 
Criterion Test

Page 5

TASK 5 (imitation)

Time: amount of time it takes to show 10 pictures

Stimuli: $\quad 10$ pictures, specifically chosen to elicit the target structure

Tester's role: holding up a picture and saying: "Listen to what I say about this picture and then say the same thing."

\section{TARGET UTTERANCES}

1 .

2.

3.

4.

5.

6.

7.

8.

9.

10.

SCORE: $\%$ 


\section{APPENDIX $K$}

\section{PLAY ACTIVITIES}

\section{Target structure "she"}

1) Name: Matching Card Game

Materials: Giant 01d Maid cards (without the 01d Maid and with cards depicting only females)

Procedures: 1) The cards were stacked so that when they were passed out, the subject received one of each pair and the investigator the other card of that pair.

2) The investigator and the subject took turns drawing cards from each other. Because of the stacked deck, each time they drew a card, they had a pair.

3) When they drew a card, they verbaliy described the pictures, such as: "She is carrying dishes and she is carrying dishes. They go together!"

4) If the subject did not follow the procedures modeled by the investigator during her turn, a prompt was used ("Say: She is carrying the dishes, etc.").

2) Name: Dress the Doll

Materials: Big, life-sized cloth doll, wig, eyes, nose, mouths (smiling and frowning), jewelry (earrings, necklace, bracelet), and a dress

Procedures: 1) The first 5 minutes of the activity were somewhat structured with the investigator and subject taking turns dressing the doll. When taking her turn, the investigator modeled sentences such as, "Now, she has a mouth, your turn to put something on!" The subject then put something on the doll and spontaneously described the new addition. However, if the subject performed the activity silentiy, the investigator pointed to the new addition, and prompted the subject saying, "Tell me about what she has now."

2) The remaining time was spent in less structured play with both the investigator and subject doing what they wanted to the doll. During this time, specific interaction techniques (as discussed earlier in this paper) were used to facilitate correct usage of the target, "she."

3) Name: Puzzles

Materials: Two puzzles with pictures of girls doing actions

Procedures: The investigator and the subject each played with a puzzle. The investigator used specific interaction techniques to facilitate correct usage of the target, "she."

4) Name: Paperdoll Play

Materials: Peabody paperdoll and clothing 


\section{Target structure "she" cont'd}

Procedures: The investigator and the subject took turns putting different outfits on the doll and telling about what she was wearing and what she was going to do in that outfit. For example, the investigator put a nightgown on the do11 and said, "She is wearing a nightgown. She is going to wash her face and she is going to brush her teeth and then she is going to bed." If the subject did not spontaneously follow the investigator's model, specific interaction techniques were used to facilitate correct usage of the target when it was the subject's turn.

5) Name: Recording Stories

Materials: cassette recorder and book

Procedures: The investigator and the subject took turns making up stories about pictures in a book. The stories were recorded and $\mathrm{Tistened}$ to by the investigator and the subject.

6) Name: Shopping

Materials: Peabody food pictures, Raggedy Ann, small plastic foods and a small plastic bag

Procedures: 1) The investigator put 6 pictures of food on the floor.

2) The investigator and subject took turns making Raggedy Ann go shopping and buy food, saying for example. "She's buying cake and apples and milk."

3) The investigator and the subject played freely with the plastic foods and plastic bag. Specific interaction techniques were used to facilitate correct usage of the target, "she," while making Raggedy Ann go shopping.

7) Name: Do11 Plays with Playdough

Materials: Life-sized dol1 and playdough

Procedures: 1) For the first 5 minutes the investigator and the subject took turns making the doll perform an activity with the playdough, and at the same time, describing her actions.

2) In the remaining time, the subject and the doll (moved by the investigator) played with the playdough. The investigator used specific interaction techniques to facilitate correct usage of the target.

\section{Target structure "they"}

1) Name: Rummy

Materials: Animal Rummy cards

Procedures: The same procedures as used with the Matching Card game, were used in playing Rummy. The only difference, was the standard sentence the investigator modeled when she got a pair ("They are camels. They go together.").

2) Name: sorting

Materials: Magnetic board, multi-colored alphabet letters; multi-colored beads, and several jars

Procedures: The investigator modeled the sorting of alphabet letters by colors, saying "They are blue, so they go here. You can help too." Then both the investigator and the subject sorted the letters, all the while talking about what they were doing. The same procedures were used with the beads and jars. 
Target Structure "they" cont'd

3) Name: Car Racing

Materials: Small race cars and blocks

Procedures: The investigator and the subject played with the race cars. The investigator structured the activity somewhat, by setting up different situations and modeling actions and accompanying descriptions. For example, the investigator set up a race ("They are racing. They crashed). devised a downhill ramp out of blocks ("They are rolling."), directed several cars to follow a particular car ("They are following the red car."), made the cars stop and go, etcetera. Specific interaction techniques were used by the investigator to encourage correct usage of the target, "they."

4) Name: Camping

Materials: 2 cars, trailer and a boat

Procedures: The investigator and the subject played freely with 2 cars, a trailer and a boat. The investigator modeled "pretend" play about people who were going camping ("They made a fire and they cooked hotdogs and they went to sleep in their sleeping bags."). Specific interaction techniques were used to facilitate correct usage of the target, "they."

5) Name: Where are they?

Materials: 4 posters (zoo, lake, schoolroom and playground)

Procedures: The investigator and the subject played a game in which one person described a picture without letting the other see it. The one who could not see the picture guessed where the children were. For example, the investigator said, "I see some kids. They are walking down a path. They see monkeys. They see lions. Where are they?" If the subject could not guess, the investigator turned the picture towards him and said, "They are at the zoo! Your turn, look at the picture and say what they are doing. Don't let me see!"

Iarget Structures "she" and "they"

The following play activities were used to facilitate both targets. "she" and "they," with adjustments made in the procedures accordingly. For example, if the activity was painted pictures in a book, then pictures with more than one person or animal performing the same activity were selected, if the target was "they." Whereas. if the target was "she," pictures with one or more females performing various activities, were selected.

1) Name: Paint ing Book

Materials: Painting book, container of water, 2 brushes

Procedures: The investigator and the subject each had his own picture to paint. The investigator modeled well-formed sentences about her picture as she painted, such as "She's riding a horse. I think she will have a black hat." The subject painted and commented about his pictures. However, if the subject did not spontaneously start talking about his picture as modeled by the investigator, then the investigator prompted the subject with a statement such as: "Tell me about what she is doing."

2) Name: Tea Party

Materials: Dolls, tea set, and water

Procedures: 1) During the first 5 minutes the investigator and subject took turns playing with the dolls and talking about what they were doing. The investigator went first and modeled a story, making the dolls perform as she used well-formed sentences to described their actions. The following is an example of a story: 
Target structures "she" and "they" cont'd

"She's pouring the tea for her sister."

"Now, she's drinking the tea." "

She's hungry, so she's going to eat."

When it was the subject's turn to make up a story, the investigator used specific interaction techniques to facilitate correct usage of the target."

2) During the remaining time, the investigator and the subject played freely with the dolls and the tea set. Again, facilitation of the target was accomplished through the use of specific interaction techniques.

3) Name: Hide and Seek

Materials: One girl doll (or several dolls) and a dollhouse

Procedures: 1) The investigator and the subject took turns hiding the dol1 (dol1s) and asking "Where is she?" (Where are they?) and finding the doll (dolls) and saying, "She is " (They are __ ).

2) The investigator and the subject played freely with the doll (dolls) and the dollhouse. Specific interaction techniques were used to facilitate the target.

4) Name: Day at the Lake

Materials: One stick-on board (picture of a lake, sand, grass, rocks, etc.), objects to stick on the board (boys and girls swimming, boys and girls sitting and standing, bal1s, sand buckets, innertubes, boats and a dock)

Procedures: 1) The investigator and the subject took turns placing various things on the board and talking about the pictures.

2) The investigator and the subject both played freely with the board and stick-on objects, while the investigator used specific interaction techniques to facilitate correct usage of the target.

5) Name: Spinning Game

Materials: Spinner, picture cards to be placed under the spinner (rooms card, food card, animal card, common objects card), and a dol1 (dol1s)

Procedures: The investigator and the subject took turns spinning the spinner and making the doll (dolls) pretend to do something related to the picture card while commenting upon what the doll (dol1s) was (were) doing. For example, if the spinner landed on the bathroom section of the room card, the investigator put the doll (dolls) on that section and said, "She is taking a bath" (They are taking a bath). Now, she is brushing her teeth (They are brushing their teeth). Now it is your turn to spin."

6) Name: Water Fun

Materials: Fisher-Price dolls, boats and wind-up frogs

Procedures: The investigator and the subject played freely with a container of water, dolls, frogs and boats. Specific interaction techniques were used to facilitate correct usage of the structure.

7) Name: Dinosaurs and the Dor1s

Materials: Dinosaurs, fence, rocks, dolls

Procedures: The investigator and the subject played freely with the dinosaurs and the dolls. Specific interaction techniques were used to facilitate correct usage of the structure. 


\section{Play Activities cont'd}

Target structures "she" and "they" cont'd

8) Name: Raggedy Ann and Andy

Materials: Smal1 Raggedy Ann and Andy Dolls

Procedures: The investigator and the subject took turns making Raggedy Ann (and Andy) do things (sleep, walk, run, jump, etcetera), as they described the actions.

9) Name: Home

Materia1s: Dollhouse, dol1s, cars, boats, etcetera

Procedures: 1) During the first 5 minutes, the investigator and the subject took turns making the dolis perform actions and then describing those actions.

2) During the remaining time, the investigator and the subject played freely with the dolls. Specific interaction techniques were used to facilitate the correct usage of the target. (With the target "they" it was very important to set up situations in which more than one person was doing something, such as, two dolls, sitting in a car, going to the store). 